Aus der Klinik für Nephrologie und Rheumatologie

(Prof. Dr.med. G. A. Müller)

im Zentrum Innere Medizin

der Medizinischen Fakultät der Universität Göttingen

\title{
Angiopoetin-1 im Kontext von EPC-vermittelter Nephroprotektion nach akuter renaler Ischämie
}

\author{
INAUGURAL - DISSERTATION \\ zur Erlangung des Doktorgrades \\ für Zahnheilkunde \\ der Medizinischen Fakultät der \\ Georg-August-Universität zu Göttingen
}

vorgelegt von

Nazif Idrizi

aus

Tetovo

Göttingen 2015 
Dekan:

Prof. Dr. rer. nat. H. K. Kroemer

I. Berichterstatter: Prof. Dr. med. D. Patschan

II. Berichterstatter: Prof. Dr. rer. nat. J. Wilting

III. Berichterstatterin: PD Dr. med. F. Czepluch

IV. Berichterstatter: Prof. Dr. dent. med. R. Mausberg

Tag der mündlichen Prüfung: 25.09.2017 


\section{Abkürzungsverzeichnis}

Ang

ANV

BP

cAMP

CFU-EC

EBM

Egr

EPC

HGF

HUVEC

IGF

IL-6

Isch

$\mathrm{kDa}$

KDR

MAPC

MW

PECAM

SEM

SVF

TGF- $\beta$

Tie

VE-Cadherin

VEGF
Angiopoetin

Akutes Nierenversagen

Blocking Peptide

Cyclic adenosine monophosphate

Colony forming unit endothelial cell

Endothelial-basal medium

Early growth response

Endothelial progenitor cell

Hepatocyte growth factor

Human umbilical vein endothelial cell

Insulin like growth factor

Interleukin-6

Ischämie

Kilo-Dalton

Kinase insert domain receptor (=Flk)

Multipotent adult progenitor cell

Mittelwert

Platelet endothelial cell adhesion molecule

Standard error of the mean

Stromal-vascular-fraction-cell

Transforming growth factor beta

Tyrosine Kinase with IgG and EGF-like repeats

Vascular-endothelial-cadherin

Vascular endothelial growth factor 


\section{Inhaltverzeichnis}

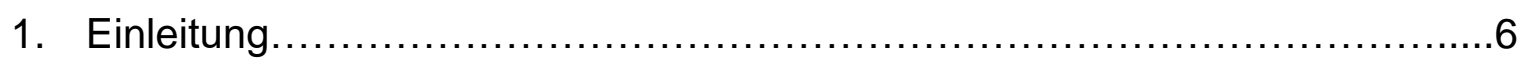

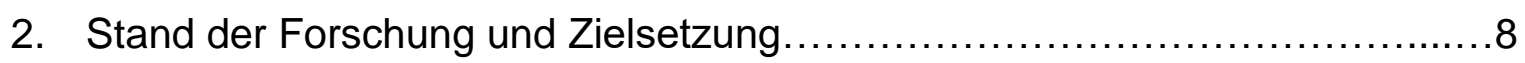

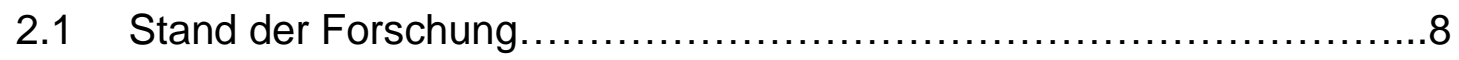

2.1.1 Akutes ischämisches Nierenversagen............................. 8

2.1.2 Endothelvorläuferzellen (Endothelial Progenitor Cells - EPCs).....9

2.1.3 Endothelvorläuferzellen und akutes Nierenversagen................12

2.1.4 Angiopoetine....................................................... 13

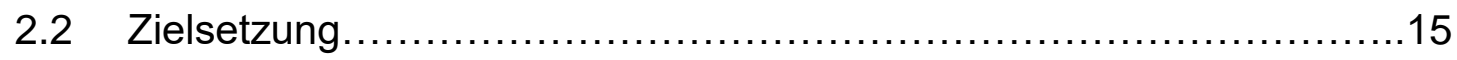

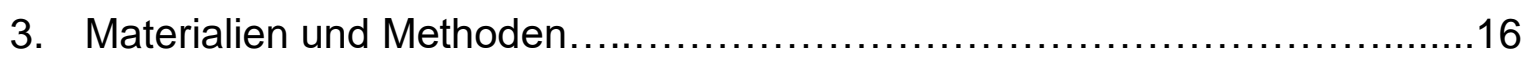

3.1 EPC-Gewinnung aus Mäusen und Zellcharakterisierung.................16

3.2 Inkubation der Zellen.................................................. 18

3.2.1 Inkubation der Zellen mit Angiopoetin-1 .........................18

3.2.2 Inkubation der Zellen mit anti-VE-Cadherin........................19

3.3 Prinzipielles Vorgehen bei der Operation...............................19

3.3.1 Anästhesie.................................................... 19

3.3.2 Operationsvorbereitung .........................................20

3.3.3 Injektion der Zellen / Ischämie....................................20

3.3.4 Blut- und Organentnahme ........................................ 21

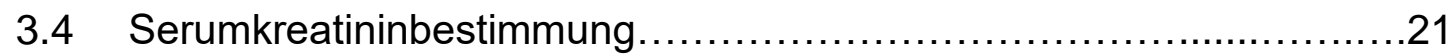

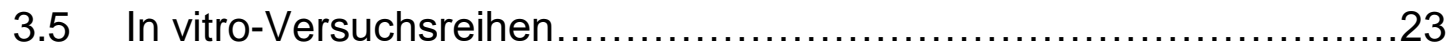

3.5.1 Bestimmung von VEGF.............................................

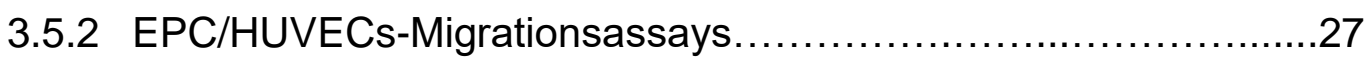

3.5.3 Zellüberlebensrate von EPCs unter Angiopoetin-1 ................27

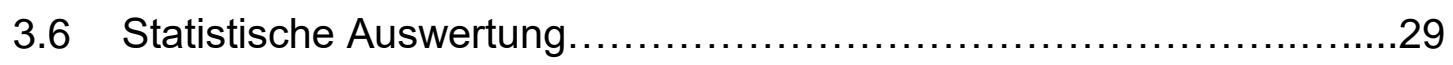

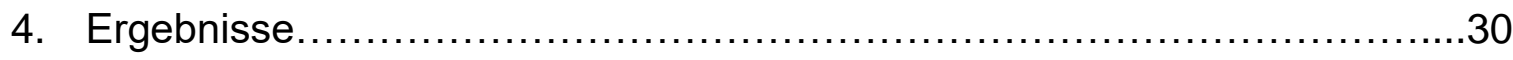

4.1 Effekte von Angiopoetin-1-behandelten markierten EPCs auf die Nierenfunktion postischämischer C57/BI6N-Mäuse ........................30

4.2 Analyse des VE-Cadherinsystems ........................................

4.3 EPC-Produktion / Sekretion proangiogener Faktoren unter dem Einfluss

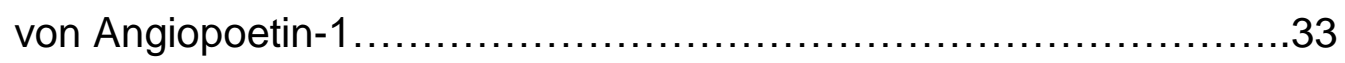

4.4 EPC-/HUVEC-Migration unter dem Einfluss von Angiopoetin-1 ...........33 
4.4.1 Migration von EPCc (direkter Migrationsassay) .......................33

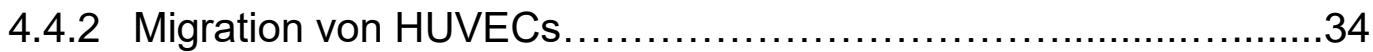

4.5 EPC-Überleben unter dem Einfluss von Angiopoetin-1 ...................35

4.6 Effekte von Angiopoetin-1-behandelten, nicht fluoreszenzmarkierten EPCs auf die postischämischer Nierenfunktion...........................36

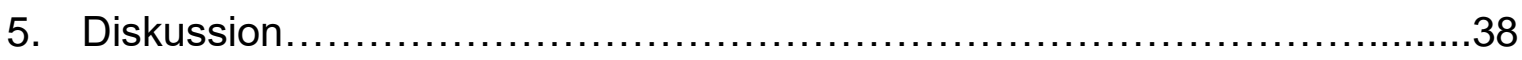

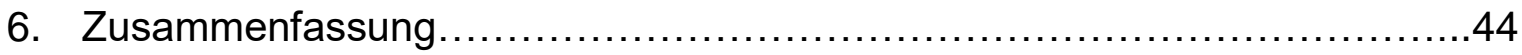

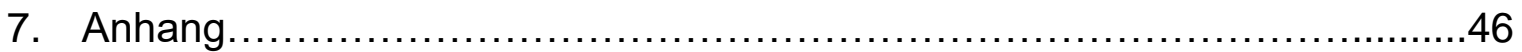

7.1 Tabellarische Zusammenfassungen der verwendeten Chemikalien

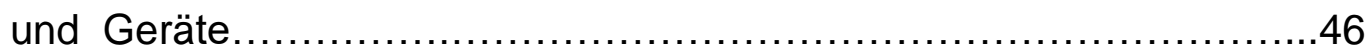

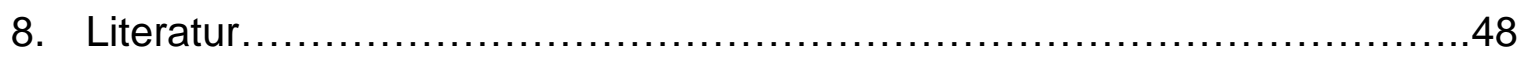




\section{Einleitung}

Diese experimentelle Arbeit beschäftigt sich mit dem therapeutischen Einsatz von Endothelvorläuferzellen zur Behandlung des akuten ischämischen Nierenversagens der Maus. Die Datenerhebung erfolgte im Rahmen eines Forschungsprojektes der Klinik für Nephrologie und Rheumatologie der Universitätsmedizin Göttingen.

Die Inzidenz des akuten Nierenversagen (ANV) beträgt bei stationären Patienten ca. 5\%, auf Intensivstationen liegt sie bei bis zu 30\% (KRIBBEN et al. 2003). Das akute Nierenversagen ist eine häufige und schwerwiegende Komplikation bei intensivmedizinisch betreuten Patienten, die Mortalität liegt bei bis zu 50\%. Die häufigste Ursache des ANV ist eine passagere Reduktion der Organdurchblutung. In diesem Kontext wird auch von einem akuten ischämischen Nierenversagen gesprochen.

Die renale Minderdurchblutung schädigt einerseits das tubuläre Epithel, andererseits verursacht sie eine relevante Entzündungsreaktion im Organ sowie eine vorübergehende Schädigung der kleinen peritubulären Blutgefäße. Diese postischämische Mikrovaskulopathie kann therapeutisch angegangen werden. Dabei kommen spezielle proangiogene Zellen, die so benannten Endothelvorläuferzellen zum Einsatz. Die Neubildung von Blutgefäßen kann im adulten Wirbeltierorganismus einerseits durch Vermehrung von reifen, ortsständigen Gefäßwandzellen stattfinden (Angiogenese), andererseits können sich unreife Vorläuferzellen in Endothelzellen differenzieren (Vaskulogenese). Endothelvorläuferzellen entwickeln sich aus pluripotenten hämatopoetischen Stammzellen im Knochenmark. Sie sind permanent im Blut vorhanden und beteiligen sich unter physiologischen und pathologischen Bedingungen sowohl an der Neubildung als auch an der Reparatur von Gefäßen (ASAHARA et al. 1997, 1999; KHAKOO und 
Finkel, 2005; URBich und DimmeleR, 2004a; URBich und DimmeleR, 2004b). Die nephroprotektive Wirkung von EPCs beim ischämischen ANV wurde bereits tierexperimentell bewiesen (PATSCHAN et al. 2006). In diesen sowie in Folgeexperimenten wurden Nieren von männlichen FVB/NJ- oder C57BI/6N-Mäusen über verschiedene Zeiträume von der Blutzufuhr abgeschnitten, wodurch ein ischämisches ANV induziert wurde. Unmittelbar nach Reperfusion der Nieren wurden dem venösen Kreislauf EPCs zugeführt und nach zwei Tagen die Nierenfunktion (Serumkreatinin als indirekter Indikator) bestimmt. Weitergehende Untersuchungen zeigten, dass die nephroprotektive Wirkung einer konstanten EPC-Menge mit zunehmender Ischämiedauer abnimmt. Es wurden mittlerweile verschiedene Substanzen identifiziert, die das nephroprotektive Potential von EPCs steigern. Im Rahmen einer bereits verteidigten Promotionsarbeit von Herrn Dr. J. Rinneburger wurde überraschenderweise gezeigt, dass die EPC-Vorbehandlung mit dem Protein Angiopoetin-1 zu einer Verschlechterung der Nierenfunktion zellbehandelter Mäuse führt. 


\section{Stand der Forschung und Zielsetzung}

\subsection{Stand der Forschung}

\subsubsection{Akutes ischämisches Nierenversagen}

Unter einem akuten Nierenversagen (ANV) versteht man eine plötzliche Verschlechterung der Nierenfunktion, immer gekennzeichnet durch einen Anstieg der Nierenretentionsparameter um wenigstens $50 \%$ des Ausgangswertes, in den meisten Fällen begleitet von einer reduzierten Urinproduktion (Oligo-Anurie) (KRIBBEN et al. 2003). Diese kann innerhalb von Stunden bis Tagen eintreten und ist prinzipiell reversibel.

Über den Anstieg der harnpflichtigen Substanzen hinaus kommt es auch zu Störungen des Elektrolyt- und Säure-Basen-Haushaltes sowie zur Hypervolämie. Das akute ischämische Nierenversagen ist die insgesamt häufigste Form des ANV. Ursache ist eine inadäquat stark ausgeprägte bzw. lang anhaltende generalisierte Minderdurchblutung des Organs. Als hierfür verantwortliche Ursachen finden sich im klinischen Altag Blutungen, eine schwere Herzinsuffizienz sowie schwere generalisierte, insbesondere bakterielle Infektionen (Sepsis). Neben der Schädigung der Tubulusepithelzellen, welcher beim akuten ischämischen Nierenversagen eine zentrale Bedeutung zukommt, sind auch Prozesse beteiligt, die auf strukturelle Veränderungen renaler Endothelzellen zurückzuführen sind (GoLIGORSKY 2005). Diese strukturellen Veränderungen imponieren in Form von Schwellungen des Endothels, wodurch die Reperfusion der Endstrombahn inhibiert wird (no-reflow Phänomen) (LEAF 1973). Eine Erholung der Nierenfunktion findet dementsprechend nur verzögert statt (BRODSKY et al. 2002). Insgesamt erholt sich die Mikrozirkulation der Nieren über einen Zeitraum von ca. 24 Stunden. Die Kapillaren verengen und erweitern sich dabei oszillierend (YAMAMOTO et al. 2002). 


\subsubsection{Endothelvorläuferzellen (Endothelial Progenitor Cells - EPCs)}

EPCs wurden erstmals 1997 von AsAHARA et al. beschrieben. In ihren Untersuchungen isolierten die Autoren $\mathrm{CD}^{34}+$-Leukozyten aus humanem Blut und kultivierten diese unter definierten Bedingungen. Die Zellen zeigten nach einigen Tagen typische Charakteristika endothelialer Zellen, und zwar sowohl morphologisch als auch hinsichtlich des Oberflächenmarkerprofils. Die Zellen wurden anschließend in immunkompromittierte Versuchstiere mit Extremitäten-Ischämien injiziert. Dabei zeigte sich, dass die funktionelle Erholung im postischämischen Gewebe schneller voranging als in Kontrolltieren, denen diese Zellen nicht injiziert wurden. Die applizierten Zellen konnten mikroskopisch in den Wänden der Kapillaren des reperfundierten Gewebes nachgewiesen werden. Die mittlerweile sehr intensiv untersuchte Population der EPCs wird wesentlich durch Zellen repräsentiert, die sich mit aller Wahrscheinlichkeit überwiegend aus pluripotenten hämatopoetischen Stammzellen im Knochenmark entwickeln (BAILEY et al. 2004; GrANT et al. 2002). Auch andere Zelltypen sind bereits als mögliche Vorläufer beschrieben worden, z.B. so genannte multipotente adulte Vorläuferzellen (multipotent adult progenitor cells - MAPCs) im Knochenmark (URBICH und DIMMELER 2004b; REYES et al. 2002), des Weiteren bestimmte Subtypen von Fettgewebezellen (cultured stromal-vascular fraction (SVF) cells) (PLANAT-BENARD et al. 2004) sowie schließlich kardiale Progenitorzellen (BeLtRAMI et al. 2003). EPCs, die sich von den genannten Zelltypen ableiten, finden sich im Blut innerhalb der Monozytenfraktion (RoMAGNANI et al. 2005). Sie exprimieren einerseits verschiedene „unreife“ (c-Kit, CD34, CD133 (RAFII und LYDEN 2003), andererseits verschiedene endotheliale Zellmarker wie KDR bzw. Flk-1 (humaner bzw. muriner Rezeptor Typ-2 für VEGF) (KHAKOO und FINKEL 2005), Tie-2 Rezeptor für Angiopoetin-1 (WAKUI et al. 2006) und CD31 (PECAM-1, platelet endothelial cell adhesion molecule-1) (BALDWIN et al. 1994). In Kultur wachsen 
sie in EBM-2 Medium auf Fibronektin-beschichteten Platten nach ca. 5-7 Tagen an. In aktuelleren Arbeiten wurden sie als Colony Forming Unit Endothelial Cells (CFU-ECs) definiert (CASE et al. 2007; YODER et al. 2007).

Obwohl die Zellen über viele Jahre als EPCs terminiert wurden und in zahlreichen experimentell-therapeutischen Studien als endotheliale Vorläufer zum Einsatz kamen, dürfte es sich bei dieser Population doch mit größter Wahrscheinlichkeit nicht um Progenitoren des reifen Endothels handeln. Es existieren verschiedene methodische Ansätze zur „EPC“- bzw. CFU-EC-Isolation und -Expansion. Eine sehr weit verbreitete Prozedur kam auch in der vorgelegten Untersuchung zum Einsatz. Sämtlichen Ansätzen ist allerdings der Umstand gemein, dass eine (Mit)kultivierung auch von Zellen myelomonozytärer Herkunft nicht augeschlossen ist. Daher ist wohl davon auszugehen, dass alle Ansätze die Kultivierung einer heterogenen Population proangiogener (myelomonozytärer) Zellen zur Folge haben. Diese wirken in vivo allerdings unzweifelhaft vasoprotektiv. In zahlreichen experimentellen Studien wurden diese, historisch als EPCs benannten Zellen zur Behandlung ischämischer Erkrankungen eingesetzt (MOUBARIK et al. 2011; ZHAO et al. 2013; SCHUSTER et al. 2004; AsAHARA et al. 1999; DEVANESAN et al. 2009; SHAFFER et al. 2006). In einer jüngeren Arbeit von Richardson wurde dieser spezielle Aspekt der Zellheterogenität sehr gut diskutiert. Schlussendlich wurde vorgeschlagen, eher von proangiogenic cells (PAC) zu sprechen (RICHARDSON UND YODER 2011). In Zukunft sollte die Terminologie sicherlich revidiert und vereinheitlicht werden. Um dem historischen Kontext treu zu bleiben, wurde in der aktuellen Arbeit jedoch am Terminus „EPCs“ festgehalten.

Bei der zweiten Hauptpopulation, den late Endothelial Outgrowth Cells (IEOCs) bzw. Endothelial Colony Forming Cells (ECFCs) handelt es sich wahrscheinlich tatsächlich 
um endotheliale Vorläufer (LIN et al. 2000; FIDINI et al. 2012). Die genauen Charakteristika dieser Population sollen jedoch aktuell nicht näher beschrieben werden.

Die Neubildung und Proliferation von Blutgefäßen findet sowohl während der Embryonalperiode als auch während des gesamten postnatalen Lebens statt. Nach der Geburt nimmt beispielsweise die Kapillardichte in Skelett- und Herzmuskulatur infolge körperlichen Trainings oder aufgrund des natürlichen Körperwachstums zu. Auch verschiedene Krankheitsprozesse, wie beispielsweise malignes Gefäßwachstums, sind durch Neoangiogenese gekennzeichnet. Prinzipiell werden zwei Arten der Gefäßneubildung unterschieden. Zum einen werden neue Arteriolen, Venolen und Kapillaren durch Proliferation ortständiger, reifer Endothelzellen und anderer Gefäßwandzellen gebildet. Zum anderen können unreife Vorläufer-(Progenitor) bzw. zirkulierende Vorläuferzellen neue Gefäße bilden. Wie bereits oben ausgeführt, wird der erste Prozeß als Angiogenese (KHAKOO und FINKEL et al. 2005; URBRICH und DimMELER 2004a), der zweite Prozess als Vaskulogenese bezeichnet (PATSCHAN et al. 2006; BAILEY et al. 2002). Bei der Vaskulogenese handelt es sich nicht, wie lange Zeit angenommen, um einen Vorgang, der auf die embryonale Phase, also auf die Phase, in der alle Organe bzw. Gewebe erstmalig ausgebildet werden, begrenzt ist. Vaskulogenese findet auch im adulten Vertebratenorganismus kontinuierlich statt. Dabei spielen endotheliale Vorläuferzellen (Endothelial Progenitor Cells, EPCs) eine herausragende Rolle. Nach derzeitigem Kenntnisstand ist wohl davon auszugehen, dass dabei eine direkte Vaskulogeneseaktivität vorzugsweise von late Endothelial Outgrowth Cells (IEOCs) bzw. Endothelial Colony Forming Cells (ECFCs) entfaltet wird. Die zweite, auch im Rahmen der vorgelegten Arbeit untersuchte Population dürfte sich an der Gefäßreparation und 
-neubildung eher über indirekte Mechanismen beteiligen. Hier sind vor allem die Freisetzung vasomodulierender Substanzen sowie proangiogener Mikrovesikel in Gefäßwandnähe zu nennen (BURGER et al. 2015).

\subsubsection{Endothelvorläuferzellen und akutes Nierenversagen}

Die ersten Untersuchungen über die regenerative Bedeutung exogen zugeführter endothelialer Zellen für das akute Nierenversagen wurden im Jahr 2002 vorgestellt (YAмAмOTO et al. 2002). Immuninkompetente Ratten (nude rats) erhielten systemische Injektionen von so benannten Human Umbilical Vein Endothelial Cells (HUVECs). Die Funktion der Niere verbesserte sich schneller als jene von entsprechenden Kontrollen. Histologisch waren die injizierten Zellen in den tubulären als auch glomerulären Kapillarwänden nachweisbar. Das Ergebnis zeigte, dass die injizierten Zellen die strukturelle und funktionelle Erholung der Kapillaren begünstigt hatten. In einer Anfang 2006 von Dr. Patschan publizierten Arbeit (PATSCHAN et al. 2006a) wurde dann erstmalig die prinzipielle therapeutische Anwendbarkeit von Endothelvorläuferzellen zur Behandlung des akuten ischämischen Nierenversagens gezeigt. Im Jahr 2009 wurde zudem eine erste Strategie erarbeitet, mit deren Hilfe das nephroprotektive Potential von EPCs beim akuten ischämischen Nierenversagen signifikant verstärkt werden kann: durch in-vitro-Vorbehandlungen der Zellen mit dem Intergrinrezeptoraktivator 8-OcAMP kam es zu einem verstärkten homing syngener muriner EPCs in die Nieren von postischämischen Mäusen. Dadurch konnten sie am Ort der Reperfusion verstärkt reparativ wirken (PATSCHAN et al. 2010). In den folgenden Jahren wurden weitere Agonisten muriner EPCs beim ANV identifiziert: Angiopoetin-2 (PATSCHAN et al. 2013) das Hormon Melatonin (PATSCHAN et al. 2012) sowie das Bone Morphogenetic Protein-5 (BMP-5) (PATSCHAN et al. 2013). Unter dem Einfluss von Angiopoetin-1 und -2 zeigten 
sich recht heterogene Veränderungen des zellulären Antwortverhaltens. Unter der Wirkung von Angiopoetin-2 kam es dosisabhängig entweder zu einer Verbesserung oder Verschlechterung der Nierefunktion zellbehandelter Mäuse, während Angiopoetin-1 den Zellen signifikant nephrodeletäre Effekte verlieh. Im Rahmen der vorliegenden Arbeit wurde die modulierende Wirkung von Ang-1 auf EPCs beim akuten ischämischen Nierenversagen nochmals im Detail untersucht. Es sei angemerkt, dass die Konsequenzen der Angioipoetin-1 Behandlung von EPCs bereits im Rahmen einer schon abgeschlossenen Promotionsarbeit (Dr. J. Rinneburger) erstmalig analysiert worden waren. In dieser Arbeit zeigte sich die benannte Verschlechterung der Nierenfunktion postischämischer Mäuse, wenn diese Ang-1 behandelte Zellen appliziert bekamen. In der nun vorliegenden Arbeit sollten die, für diese Funktionsverschlechterung verantwortlichen Mechanismen genauer untersucht werden.

\subsubsection{Angiopoetine}

Angiopoetine sind Proteine, welche essentielle Funktionen im Rahmen der vaskulären Homöostase und Regeneration vermitteln. Bislang sind 4 Hauptvertreter der Gruppe sowie 8 Angiopoetin-ähnliche Proteine (Angiopoietin-related proteins) identifiziert worden (LINARES UND ChAPARRO 2014; SANTULlI 2014). Zu den Angiopoetin-ähnlichen Proteinen gehören: ANGPTL 1 bis 7 und das Angiopoetin-ähnliches Proteinen 8/Betatrophin. Angiopoetin-ähnliche Proteine sind strukturell verwandt mit den Angiopoetinen. Es handelt sich hierbei um spezielle Eiweiße mit $\mathrm{N}$-terminalen superspiralisierten und C-terminalen fibrogenartigen Domänen. Anders als die Angiopoetine binden sie nicht Tie-2. Sie weisen eine Enzyminhibitor-Aktivität auf. Ihnen kann bei diversen biologischen Prozessen eine Beteiligung zugeordnet werden. So spielen sie zum Beispiel bei der Entwicklung multizellulärer Organismen, der Zelldifferenzierung, der Protein-Homooligomerisierung und 
der negativen Regulation von Lipoprotein-Lipaseaktivitäten und von apoptotischen Prozessen eine Rolle. Es ist dabei zu beachten, dass die Angiopoetine 3 und 4 so benannte Interspezies-Orthologe sind: das murine Angiopoetin-3 entspricht dem humanen Angiopoetin-4. Die Proteine binden extrazellulär an den Tie-2-Rezeptor (BLANN UND SCHON et al. 2005). Angiopoetin-1 und -2 sind die bislang am detailliertesten untersuchten Vertreter der Hauptfamilie. Ihr ausbalanciertes Wechselspiel der Aktivierung von Tie-2 reguliert die Gefäßbetthomöostase. Die spezifischen Liganden des Tie-2-Rezeptors sind eine neue Gruppe von Wachstumsfaktoren mit hoher Spezifität für das vaskuläre Endothel. Bindet Angiopoetin als Ligand an den Tyrosikinase-Rezeptor Tie-2, so wird eine Phosphorylierung ausgelöst. Durch diese wird die Integrität des Gefäßbetts aufrechterhalten und das Überleben der Endothelzellen sichergestellt. Die Gefäße sind stabil, impermeabel, antiadhäsiv und antithrombotisch (PFAFF et al. 2006). Ang-1 und Ang-4 wirken als aktivierende Liganden (Agonist), während Ang-2 und Ang-3 spezifisch als blockierende Liganden (Antagonist) wirken. Beide Moleküle sind Glykoproteine mit einem ungefähren Molekulargewicht von 70 kDa (MAISONPIERRE et al. 1997). Eine Bindung von Ang-1 an Tie-2 induziert die rasche Rezeptorautophosphorylierung in Endothelzellen und führt somit zur Aktivierung intrazellulärer Signalkaskaden. Die distal in der Signalkaskade induzierten Effekte durch den aktivierten Tie-2-Rezeptor steuern Endothelzellüberleben, Gefäßstabilität, Endothelzellmigration und verminderte Thrombogenität (PFAFF et al. 2006). Die biologischen Konsequenzen der Wirkungen von Angiopoetin-1 werden nach wie vor intensiv untersucht. Es konnte gezeigt werden, dass Angiopoetin-1 im Mäusemodell in-vivo den Blut- und Lymphgefäßumbau sowie die Wundheilung anregt. Außerdem supprimiert Angiopoetin-1 die Apoptose von Endothelzellen und fördert die Zellmigration, -proliferation und -differenzierung (BRINDLE et al. 2006). Diese Wirkung von Angiopoetin-1 wird der Er- 
höhung der Transkriptionsrate von Egr-1 (early growth response 1) zugeschrieben. Zusammen mit VEGF kommt es zu einer synergistischen Wirkung auf Egr-1 und damit zur Migration, Proliferation und Formation von Endothelzellen (ABDEL-MALAK et al. 2009). Die Beobachtungen, dass Angiopetin-1 den Blut- und Lymphgefäßumbau stimuliert sowie antiapoptotische Effekte in Endothelzellen vermittelt, ließen schlussfolgern, dass das Protein agonistische Effekte auf EPCs bei ANV entfaltet. Umso überraschender waren die in der Promotionsarbeit von Herrn Rinneburger gesehenen, nephrodeletären Konsequenzen der EPC-Behandlung mit Ang-1.

\subsection{Zielsetzung}

Das Ziel der vorgelegten Arbeit bestand in der genaueren Analyse der Effekte von Angiopoetin-1 auf EPCs beim iANV. Im Rahmen einer bereits abgeschlossener Promotionsarbeit von Herr Dr. J. Rinneburger wurde gezeigt, dass das Protein zur Verschlechterung der postischämischen Nierenfunktion EPC-behandelter Mäuse führt, wenn die Zellen mit dem Mediator vorbehandelt werden. Der Grund für diese Effekte blieb bis zum Abschluss dieser Arbeit unklar. 


\section{Materialien und Methoden}

\subsection{EPC-Gewinnung aus Mäusen und Zellcharakterisierung}

Alle tierexperimentellen Eingriffe erfolgten als Bestandteil des Tierversuchsverfahrens (G49/07). Die für die Untersuchungen verwendeten Zellen wurden nach einem Protokoll isoliert, welches bereits in zahlreichen eigenen sowie auch laborfremden Untersuchungen zum Einsatz kam (CANTALUPPI et al. 2012; GOLIGORSKY et al. 2010; KAWAMOTO et al. 2002; PATSCHAN et al. 2015).

Die Isolation der Zellen erfolgte unter sterilen Bedingungen aus Vollblut und Milzhomogenaten. Präoperativ wurden männlichen 8-12 Wochen alten C57BI/6N-Mäusendurch eine Injektion von Xylazin (Analgetikum) und Ketamin (Narkotikum) in die Peri-

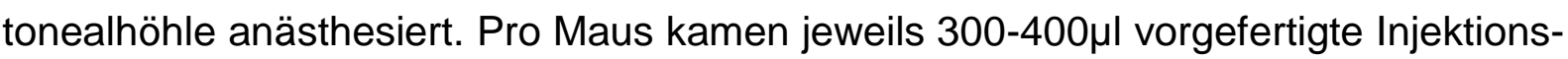
lösung zum Einsatz $(6,8 \mathrm{ml} 0,9 \% \mathrm{NaCl}+520 \mu \mathrm{l}$ Anästhesiegemisch der Firma SIGMAALDRICH -10ml enthalten 800mg Ketamin $\mathrm{HCl}$ und 120mg Xylazin $\mathrm{HCl}$, Katalog $\mathrm{Nr}$.: K-113). Nachdem die Maus sicher anästhesiert war, wurde ein vertikaler Bauchschnitt durchgeführt und anschließend das Zwerchfell freigelegt. Das Bewusstsein wurde mittels Einkneifen der Schwanzspitze getestet. Mit einer Spritze wurde transdiaphragmal Blut aus dem Herzen entnommen. Zur Gerinnungshemmung enthielt die Spritze einen Tropfen Heparin (Heparin-Natrium 25.000, Firma RATIOPHARM, Katalog Nr.:

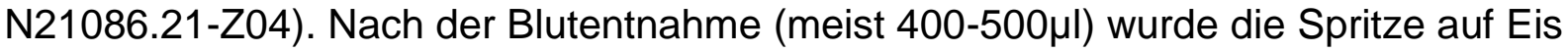
gelegt. Anschließend wurde die Milz entnommen und in ein 15ml-Greiner-Röhrchen überführt sowie in 2ml EBM-2 (EBM-2, Endothelial Basal Medium-2, Firma LONZA, Katalog Nr.: CC-3156) mittels eines Spritzenkolbens homogenisiert. Sowohl die Vollblutprobe als auch die Milzhomogenatüberstände wurden gemeinsam in ein $50 \mathrm{ml}$ Greiner-Röhrchen auf Biocoll separating solution (Firma BIOCHROM AG, Katalog Nr.: 
L6115) der Dichte 1,077g/ml überschichtet. Zur Dichtetrennung wurden die GreinerRöhrchen dann für 30 Minuten bei 1.400U/min (ohne „Bremse“) zentrifugiert (Zentrifuge der Firma Beckmann, Typ:G5-6R). Im Anschluss daran wurde die mononukleäre

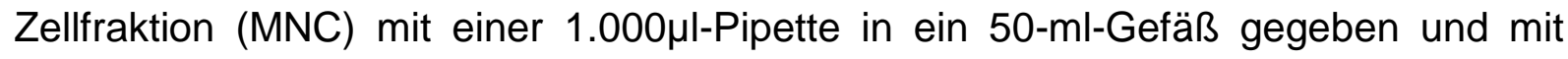
EBM2-Medium auf $40 \mathrm{ml}$ aufgefüllt. Danach wurden die Zellen für 10 Minuten bei 1400 U/min (mit „Bremse“) zentrifugiert und anschließend in 2ml EBM-2 resuspendiert. Die Zellen wurden dann in einer Neubauerkammer gezählt und so verdünnt, dass jeweils ca. 4 ×106 EPCs in $2 \mathrm{ml}$ EBM-2 verdünnt waren. Des Weiteren wurden nun je $2 \mathrm{ml}$ der Suspension in eine Vertiefung einer mit Fibronektin (Firma SIGMA-ALDRICH, F0895-1MG) beschichteten 6-well-Kulturplatte pipettiert. Die Kulturplatten wurden dann bis zum ersten Mediumwechsel nach 3 Tagen bei $37^{\circ} \mathrm{C}$ inkubiert.

Nach weiteren zwei Tagen wurden sie in ausgesuchten Experimenten einer acLDL- / BS-1 Lektin-Färbung unterzogen. Zu diesem Zweck wurden sie nach Absaugung des Mediums einfach mit PBS gewaschen. Anschließend wurden 200 $\mu$ l Medium und $2 \mu \mathrm{l}$ acLDL (Firma INVITROGEN, Katalog Nr.: L3484) in einer Konzentration von 10 $\mathrm{g} / \mathrm{ml}$ hinzugegeben und für $1 \mathrm{~h}$ bei $37^{\circ} \mathrm{C}$ im Wärmeschrank inkubiert. Nach erneuter PBSWaschung wurde eine Fixierung mit 2\%-iger Formalinlösung für 10 Minuten bei Raumtemperatur unter Lichtausschluss durchgeführt. Nach nochmaliger zweifacher PBSWaschung erfolgte die Zugabe von 500 $\mu$ I PBS-BSA 1\% und $5 \mu$ I BS-1-Lectin (FITClabeled; BS-1: (Firma SIGMA, Katalog Nr.: L9006). Anschließend wurde die Suspension bei $37^{\circ} \mathrm{C}$ im Wärmeschrank für mindestens 2 Stunden inkubiert und danach zweifach mit PBS gewaschen. Bis zur abschließenden Färbung in fand eine Lagerung bei $4^{\circ} \mathrm{C}$ statt. Abschließend wurden die Zellen fluoreszenzmikroskopisch betrachtet, als EPCs wurden acLDL+/BS-1+ Zellen identifiziert. Die benannten Schritte wurden nicht 
im Rahmen jeder Zellisolation, sondern nur initial durchgeführt um die Reliabilität der bereits etablierten Methode erneut zu bestätigen.

Die Weiterbehandlungen für die Injektionsexperimente wurden wie folgt durchgeführt: die angezüchteten Zellen wurden nach Absaugen des Mediums mit jeweils $200 \mu \mathrm{l}$ Trypsin-Lösung für 5 Minuten bei $37^{\circ} \mathrm{C}$ inkubiert. Anschließend wurden sie mit $500 \mu \mathrm{l}$ EBM-2 von der Kulturplattenfläche „abgespült“ und in einem 50ml Greiner Röhrchen für 10 Minuten bei $1.400 \mathrm{U} / \mathrm{min}$ zentrifugiert. Je $50 \mu \mathrm{g}$ eines speziellen Farbstoffes (Cell

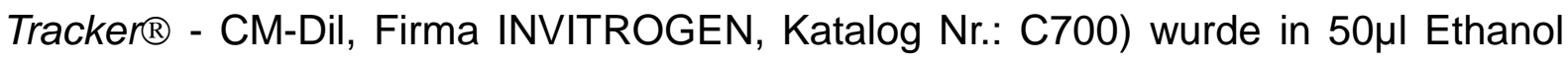
(100\%) gelöst. Die Ethanollösung wurde mit EBM-2 in einem Verhältnis 1:1000 verdünnt. Die Zellen wurden in $1 \mathrm{ml}$ dieser Lösung resuspendiert, für 5 Minuten bei $37^{\circ} \mathrm{C}$ inkubiert und danach für 15 Minuten auf Eis gelegt. Nach 15 Minuten wurde eine erneute Zellzählung in der Neubauerkammer durchgeführt. Die Suspension wurde mit EBM-2 auf $12 \mathrm{ml}$ aufgefüllt und erneut für 10 Minuten bei 1.400U/min zentrifugiert. Danach wurde eine Konzentration von $0,5 \times 10^{6}$ Zellen je $50 \mu$ l durch Resuspension in EBM-2 erstellt und in die Injektionsspritze für die Operationen aufgezogen. Bis zur Injektion wurde der Inhalt abgedunkelt auf Eis gelagert.

\subsection{Inkubation der Zellen}

\subsubsection{Inkubation der Zellen mit Angiopoetin-1}

Vor der Injektion wurden die Zellen mit Cell Tracker $®$ für eine Stunde in einem 50ml

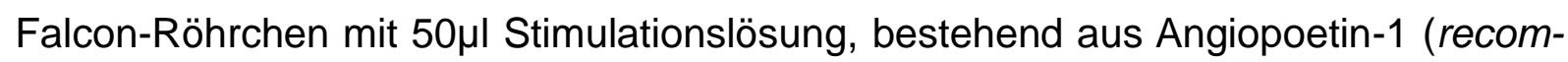
binant human Angiopoetin-1, Firma Bicoat, Katalog Nr.:4921-10) in einer Konzentration von $200 \mathrm{ng} / \mathrm{ml}$ bei $37^{\circ} \mathrm{C}$ inkubiert. (KIM et al. 2000; Koblizek et al. 1998). Nach Abzentrifugieren der Lösung wurde mit der Zählung begonnen. 


\subsubsection{Inkubation der Zellen mit anti-VE-Cadherin}

Vor der Injektion wurden die mit Cell Tracker ${ }^{\circledR}$ markierten Zellen mit einer Stimulationslösung bestehend aus VE-Cadherin in einer Konzentration von 40ng/ml +/- CycloArg-Gly-Asp-d-Phe-Val in einer Konzentration von 500nM/I (ENZO Life science, Cat: BML-AM 100-0001) für 60 Minuten bei $37^{\circ} \mathrm{C}$ inkubiert. Nach Abzentrifugieren der Lösung wurde mit der Zählung begonnen.

\subsection{Prinzipielles Vorgehen bei der Operation}

Es handelt sich um eine tierexperimentelle Studie. Die Durchführung der notwendigen Operationen wurde durch den Tierschutzbeauftragten Herrn Prof Dr. H. Jarry persönlich überprüft und eine „Ausnahmegenehmigung“ des Landes Niedersachsen wurde erteilt. Pro Tier wurden im Rahmen aller Experimente jeweils zwei Operationen im Abstand von 48h durchgeführt. Bei der ersten Operation wurde die Ischämie an der linken Niere für 40 Minuten mittels Gefäßklemmen erzeugt. Um den Gefäßstiel der rechten Niere wurde eine Nahtschlinge platziert. Nach Ablauf der 40 Minuten und Reperfusion der linken Niere durch Entfernen der Klemme wurde der entsprechende Versuchs- 0der Kontrollstoff in die Vene der rechten Nieren injiziert und diese resiziert. Bei der zweiten Operation (48h später) wurde Blut zur Analyse der Nierenfunktion (Serumkreatininwert) sowie die jeweils in den Tieren belassene linke Niere zur konventionellen histologischen Analysen gewonnen bzw. verwendet.

\subsubsection{Anästhesie}

Das Anästhetikum (Injektionslösung: 6,8ml 0,9\% NaCl $+520 \mu$ l eines Narkosegemisches der Firma SIGMA-ALDRICH (10ml enthalten $800 \mathrm{mg}$ Ketamin $\mathrm{HCl}$ und 120mg Xylazin $\mathrm{HCl}$ ) Katalog Nr.: K-113) wurde jeweils nach negativer Aspirationskontrolle in 


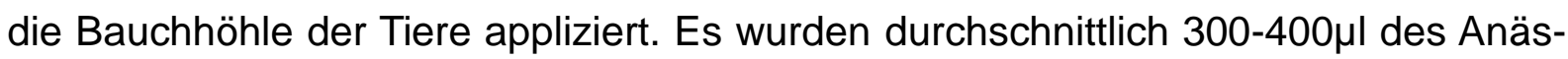
thetikums injiziert. Die anästhetisierte Maus wurde für 10-15min zurück in den Käfig gelegt, bis eine tiefe Sedierung vorlag.

\subsubsection{Operationsvorbereitung}

Nachdem die Maus anästhesiert war, wurde sie aus dem Käfig entnommen und auf einer Styroporplatte mit Klebestreifen fixiert. Die Tiefe von Sedierung und Anästhesie wurde nochmals geprüft. Das Bauchfell wurde mit einer Hautdesinfektionslösung desinfiziert. Zunächst wurden die Hautschicht und danach die Muskelschicht median auf einer Länge von ca. $2 \mathrm{~cm}$ eingeschnitten. Beim Eröffnen des Bauchraumes musste eine Verletzung innerer Organe, insbesondere des Darms, vermieden werden. Die Wundränder wurden mittels angefeuchteter Tüchern (physiologische Kochsalzlösung) feucht gehalten. Nun wurde zuerst die linke Niere mit Hilfe von Wattestäbchen, ebenfalls mit physiologischer Kochsalzlösung angefeuchtet, aufgesucht und die Hilusgefäße in stumpfer Präparationstechnik dargestellt. Zur besseren Darstellung wurden die Darmschlingen auf ein feuchtes Tuch außerhalb der Bauchhöhle gelegt und abgedeckt um Austrocknung zu vermeiden.

\subsubsection{Injektion der Zellen / Ischämie}

Die Blutzufuhr der linken Niere wurde dann durch das Anbringen einer Gefäßklemme am Hilus unterbrochen. Der Zeitpunkt wurde notiert. Nach dem Abklemmen wurde die rechte Niere aufgesucht und aus ihrem Fettlager gelöst, um eine Ligatur am Nierengefäß anzubringen. Die Gefäßklammer an der linken Niere wurde nach 40 Minuten Ischämiedauer entfernt. Nach beginnender Reperfusion wurde in einem maximalen

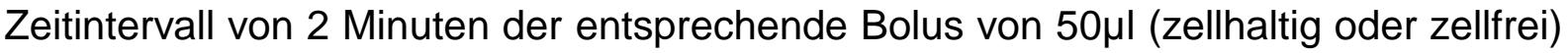
in die rechte Nierenvene injiziert. Die Einstichstelle musste distal der Ligatur liegen. 
Nach Entfernen der Spritze wurde die eventuelle Blutung durch sofortiges Zuziehen der Ligatur gestoppt und mittels mehrfacher Knotung gesichert. Nach Sitzkontrolle der Injektionsnadel wurde die rechte Niere vollständig entfernt. Die Darmschlingen wurden in die Bauchhöhle remobilisiert und anschließend erfolgte der dichte Verschluss durch zweischichtige (Muskelschicht und Hautschicht) fortlaufende Nahttechnik. Jede Maus wurde nach dem Verschluss der Bauchhöhle in einen neuen Käfig gelegt.

\subsubsection{Blut- und Organentnahme}

Die Anästhesie erfolgte auf gleiche Weise, wie bereits dargestellt. Die Mäuse wurden dementsprechend nach 48h getötet, um Blut und Nieren gewinnen bzw. entnehmen zu können. Der Bauchraum wurde eröffnet, zusätzlich zum medianen Bauchschnitt wurde ein T-Schnitt durchgeführt, dessen laterale Extension subdiaphragmal angelegt war. Mit einer Insulinspritze wurde das schlagende Herz durch das Zwerchfell punktiert

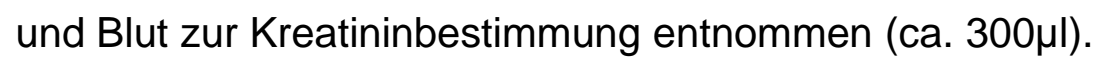

Nach erfolgreicher Blutentnahme erfolgte die Dekapitation der Maus und die Entnahme der linken Niere zur histologischen Auswertung.

\subsection{Serumkreatininbestimmung}

Um eine Aussage über die filtrativen und sekretorischen Funktionen der Nieren treffen zu können, werden in der klinischen Praxis die Serumkonzentrationen so genannter Retentionsparameter bestimmt. Ein bewährter Analyt ist hierbei das Kreatinin. Es ist prinzipiell nicht möglich, anhand der Serumkreatininkonzentration eine exakte Aussage über die exkretorische Nierenfunktion zu treffen. Der Parameter erlaubt eine näherungsweise Abschätzung dieser Funktion. Allerdings handelt es sich noch immer um den in der Klinik am breitesten angewendeten Parameter zur Nierenfunktionsanalyse. Bislang sind noch keine sensitiveren Parameter fest etabliert. 
Kreatinin wird aus in der Skelettmuskulatur für die Energiegewinnung abgebautem Kreatinphosphat gebildet. Die Serumkonzentration des Kreatinins steigt üblicherweise erst ab einer ca. $60 \%$-igen renalen Funktionsminderung an. In der Niere wird Kreatinin weder tubulär reabsorbiert noch sezerniert, so dass sich die glomeruläre Filtrationsrate anhand der Kreatininkonzentrationen im Blut beurteilen lässt. Das gewonnene Vollblut wurde zeitnah zur Entnahme bei $37^{\circ} \mathrm{C}$ für 10 Minuten im Wasserbad inkubiert und anschließend für 30-45 Minuten bei Raumtemperatur ruhen gelassen. Dann erfolgte die Zentrifugation bei $1.400 \mathrm{U} / \mathrm{min}$ für 10 Minuten. Anschließend konnte das Serum abpipettiert werden. Das Serum wurde sofort in Eppendorfgefäße überführt und bei $-80^{\circ} \mathrm{C}$ tiefgefroren. Die Bestimmung der Kreatininwerte erfolgte mittels des Kreatinin-Testverfahrens LT-SYS der Firma „Labor und Technik Eberhard Lehmann“ (Creatinin PAP, enzymatisch, flüssig, Bestellnummer: LT-CR 0101) und einem Photometer (Schimadzu Spectrophotometer UV-120-01). Die Reagentien (Reagenz 1: EHSPT 0,4mmol/l, Creatinase $\geq 10 \mathrm{kU} / \mathrm{l}$, Sarcosinoxidase $\geq 3,5 \mathrm{kU} / \mathrm{l}$, Ascorbinatoxidase $\geq 1 \mathrm{kU} / \mathrm{l}$; Reagenz 2 : 4-Aminoantipyrin 2,95mmol//, Peroxidase $\geq 4 \mathrm{kU} / \mathrm{l}$, Creatininase $\geq 150 \mathrm{kU} / \mathrm{l}$ ) wurden gebrauchsfertig geliefert. Für jede Probe sowie für Standard und Leerprobe wurden $600 \mu \mathrm{l}$ Reagenz 1 benötigt. Die Serumproben wurden in einem 1,5ml Eppendorf-Röhrchen mit destilliertem Wasser im Verhältnis 1:5 bis 1:10 verdünnt. Das Zielvolumen betrug $50 \mu \mathrm{l}$. Es wurden also je $10 \mu \mathrm{l}$ Serum mit je $40 \mu \mathrm{l}$ destiliertem Wasser verdünnt bzw. $5 \mu \mathrm{l}$ Serum mit $45 \mu$ destiliertem Wasser gemischt. Außerdem wurden $50 \mu l$ der KreatininStandardlösung (Kreatinin 2,00mg/dl) in ein 1,5ml Eppendorf - Röhrchen gegeben. Die Komponenten wurden dann im Wasserbad auf $37^{\circ} \mathrm{C}$ erwärmt. Die PhotometerKüvetten wurden mit den Serumproben und der Standardprobe sowie mit jeweils $600 \mu l$ Reagenz 1 gefüllt. Zusätzlich wurden $600 \mu l$ Reagenz 1 als Leerprobe in eine Küvette 
eingebracht. Die Komponenten wurden gut gemischt und für 3 Minuten bei $37^{\circ} \mathrm{C}$ inku-

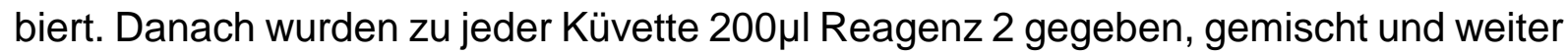
temperiert. Die Absorptionsmessung zur Ermittlung des Extinktionswertes E1 wurde 90 Sekunden nach der Zugabe von Reagenz 2 bei $550 \mathrm{~nm}$ durchgeführt.

Die Absorptionsmessung zur Ermittlung des Extinktionswertes E2 wurde 120 Sekunden nach der ersten Absorptionsmessung bei 550nm durchgeführt.

Der Serumkreatininwert errechnete sich aus dem Sollwert des Standards, multipliziert mit dem Quotienten aus der Differenz von E2 und E1 (dE) der Analyse und dE des Standards.

\subsection{In vitro-Versuchsreihen}

\subsubsection{Bestimmung von VEGF}

Vascular Endothelial Growth Factor (VEGF) wird von EPCs produziert und sezerniert. Potentiell ist dieser Mediator in der Modulation des postischämischen perivaskulären Milieus involviert. Aus diesem Grund wurden der benannte Faktor im Medium von kultivierten EPCs untersucht / quantifiziert. Hierfür wurde das ELISA-Verfahren verwendet.

ELISA ist die Abkürzung für Enzyme-linked Immunosorbent Assay und dient klassischerweise zur Detektion gesuchter / bekannter Antigene. Die zu untersuchende Probe wird mit den passenden Antikörpern inkubiert. Dadurch bilden sich bei vorhandenen, passenden Antigenen und Antikörpern Antigen-Antikörper-Komplexe. Zur Verifizierung der Antigen-Antikörper-Spezifität und zum Ausschluss von fehlerhafter Komplexbildung durch Störfaktoren wird zudem eine Kontrollgruppe angefertigt. Hierbei befindet sich idealerweise kein Antigen in der Probe. So bildet sich bei regelrechtem Ablauf kein Antigen-Antikörper-Komplex. Sichtbar werden die Antigen-Antikörper- 
Komplexe durch Zugabe des zum Antikörper passenden Markers. Dadurch wird die Menge der Antigene durch eine quantitativ bewertbare Färbung sichtbar, das heißt die Farbreaktion ist proportional zur Konzentration der Antigene.

Die Konzentrationsbestimmung mittels ELISA beruht auf der Verwendung einer festen Phase als Reaktionsort, bei der es sich zumeist um eine Polystyren-Mikrotiterplatte handelt. Auf dieser ist der vorgegebene Reaktionspartner, ein Antigen oder Antikörper, gebunden. In der vorliegenden Arbeit wurde dafür eine 96-well-Platte verwendet, die beispielsweise anti-mouse VEGF beschichtet wurde. Eine Inkubation nach Zugabe der Probe bewirkt, dass das zu untersuchende Substrat ebenfalls auf der festen Phase fixiert wird. Dies wird mit Hilfe eines spezifischen Detektionsantikörpers nachgewiesen, welcher einen enzymatischen Farbumschlag des zunächst farblosen Substrats bewirkt. Dieser Farbumschlag kann mittels Photometer oder mittels einer Fluoreszenzreaktion gemessen werden. Über die Intensität des Farbumschlags ist dann eine Aussage möglich, in welcher Konzentration das Substrat in der Probe vorlag. Grundlage für diese quantitative Auswertung ist die Eichung des Testverfahrens. Hierfür wird zusätzlich zur Leerprobe eine Standardprobe bei bekannter VEGF-Konzentration getestet. Trägt man nun für die Standardproben die bekannte VEGF-Konzentration gegen die dabei gemessene Extinktion des Photometers auf, so erhält man die sogenannte Standardkurve. Betrachtet man nun die Extinktion des Photometers bei der Versuchsreihe, so kann mit Hilfe dieser Standardkurve aus der Extinktion des Photometers auf die Konzentration an VEGF in den zu untersuchenden Proben rückgeschlossen werden. 
Es wurde das RayBio® Mouse VEGF ELISA-Test (RayBio® Mouse VEGF ELISA Kit; RAYBIOTECH, INC.; Kat.-Nr.: ELM-VEGF-001) verwendet. Die Funktionsweise ist bereits unter Punkt 3.6 grundlegend beschrieben. Die Absorption wurde mit Hilfe des ELISA-Mikrotiter-Platten-Reader (Teca Spectra; Photometer der Firma TECAN) bestimmt. Die Materialien wurden im Kit weitestgehend gebrauchsfertig geliefert.

- Reagenz A

- Reagenz B

- Reagenz C

- Reagenz D

- Reagenz E

- Reagenz F

- Reagenz G

- Reagenz H

- Reagenz I
96-well-Platte, anti-mouse VEGF beschichtet

25ml Pufferkonzentrat

rekombinanten murinen VEGFs

30ml 0,09\% Natriumazid Lösung

15ml Pufferkonzentrat

anti-mouse VEGF

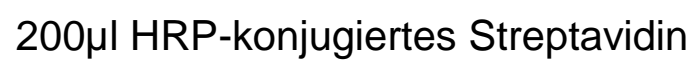

TMB-Reagenz

8ml 0,2M Schwefelsäure

Die Testung wurde nach etablierter Methodik bei Raumtemperatur durchgeführt.

Reagenz E wurde fünfmal mit Aqua dest. verdünnt. Es wurden doppelte Standardproben verwendet. Für die Anfertigung einer $25 \mathrm{ng} / \mathrm{ml}$ Standardlösung wurde Reagenz C

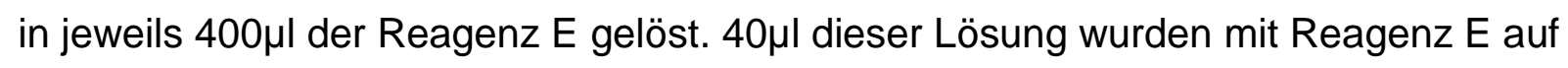
$1 \mathrm{ml}$ verdünnt. Die Lösung von 1ng/ml VEGF wurde für die Standardlösungen verwendet.

Diese Ausgangslösung wurde für die Herstellung der Standardlösungen in den verschieden Konzentration weiter verdünnt. Es ergeben sich folgende Werte: 400pg/ml; $160 \mathrm{pg} / \mathrm{ml} ; 64 \mathrm{pg} / \mathrm{ml} ; 25,6 \mathrm{pg} / \mathrm{ml} ; 10,2 \mathrm{pg} / \mathrm{ml} ; 4,1 \mathrm{pg} / \mathrm{ml}$ + Reagenz E 0pg/ml. 
Es folgte als Vorbereitung die Herstellung der Waschlösung, Antikörper-Detektionslösung und Streptavidinlösung entsprechend der Arbeitsanweisung. Alle VEGF-Mikroplatten wurden dreimal mit Reagenz B und einer Multikanalpipette der Firma EPPENDORF (Multipette® plus; EPPENDORF; Kat.-Nr.:4981 000.019) gewaschen und anschließend luftgetrocknet. Der eigentliche Test gliedert sich in 9 Schritte.

Zuerst wurden $100 \mu \mathrm{l}$ eines jeden Standards Reagenz C und der Proben in die Vertiefungen der 96-well-VEGF-Mikroplatte pipettiert. Diese wurde dann für 2,5 Stunden bei Raumtemperatur, dynamisch und abgedeckt inkubiert (rotierender Plattformschüttler Rotamax 120; Firma Heidolph; Kat.-Nr.:544-41200-00).

Nach Inkubation wurden die Lösungen abpipettiert und die Vertiefungen mit dem 300 $\mathrm{\mu l}$ Reagenz B viermal gewaschen.

Pro Vertiefung wurden $100 \mu \mathrm{l}$ der Antikörper-Detektionslösung (biotinyliertes antimouse VEGF, murine VEGF-AKs, Reagenz F) hinzugegeben und für eine Stunde bei Raumtemperatur inkubiert. Es folgte Reagenz B zur Ablösung von ungebundenem Re-

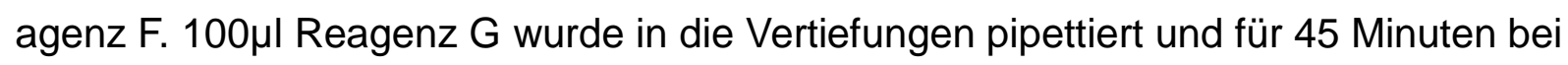
Raumtemperatur, dynamisch und abgedeckt inkubiert. Gefolgt von einer Waschung mit Reagenz B. Dann wurden 100 $\mu$ l von Reagenz H in die Vertiefungen pipettiert und für 30 Minuten bei Raumtemperatur ohne Schwenken im Dunkeln inkubiert. Die Intensität der Färbung wird als proportional zur VEGF-Konzentration (wie oben beschrieben) angenommen. Zum Arretierung der Farbreaktion wurden 50 $\mu$ Reagenz I in jede Vertiefung pipettiert. Abschließend erfolgte sofort die photometrische Bestimmung der Konzentration bei 450nm. (ELISA-Mikrotiter-Platten-Reader Teca Spectra; Firma TECAN). Funktion und Extinktion wurde bei der Kreatininbestimmung bereits beschrieben. 
Parallel dazu wurden im selben Verfahren auch HGF (HGF mouse ELISA der Firma ABCAM; Kat.-Nr.: 100686) und IGF-1 (IGF mouse ELISA der Firma ABCAM Kat.-Nr.: 100696) im ELISA untersucht. Die benannten Untersuchungen wurden jedoch nicht vom Promovenden mit durchgeführt und eine Darstellung der Resultate soll daher in dieser Arbeit auch nicht erfolgen.

\subsubsection{EPC-/HUVECs-Migrationsassays}

Murine EPCs bzw. humane reife Endothelzellen (HUVECSs - Human Umbilical Vein Endothelial Cells) (Kat.-Nr.:PCS-100-013; Firma ATCC) wurden in 24-well-Platten kultiviert, bis der gesamte Kulturplattenboden von Zellen bedeckt war. Mittels eines standardisierten Stempels wurde eine artifizielle Wundfläche geschaffen. Diese wurde mit einer 200-fachen Vergrößerung zu den Zeitpunkten 0 und 24 Stunden fotographiert. Die Wundflächengröße wurde jeweils mit dem Programm ImageJ (vers. 1.49n) quantifiziert und die Wundflächenreduktion prozentual ermittelt. Die reifen humanen Endothelzellen wurden zudem für eine Stunde mit Überstand muriner EPCs (Mouse endothelial Progenitor Cell Culture) (Kat.Nr.: 66110-37; Firma Celprogen) behandelt, letztere wurden zuvor mit Angiopoetin-1 in einer Konzentration von $250 \mathrm{ng} / \mathrm{ml}$ für eine Stunde inkubiert.

\subsubsection{Zellüberlebensrate von EPCs unter Angiopoetin-1}

Apoptose ist ein mehrstufiger zellulärer Prozess, der erste Schritt der Kaskade beinhaltet ein Schrumpfen der Zellen, welches als Pyknose bezeichnet wird und eine Trennung von den Nachbarzellen bewirkt. Nach dem Kollaborieren des Zytoskleletts löst sich die Kernmembran auf. Der Nucleolus desintegriert, nachdem das Chromatin an seiner Peripherie kondensiert ist. Anschließend wird der Zellkern in internukleosomale 
Segmente fragmentiert, was unter dem Begriff Karyorhexis geführt wird. Den Abschluss bildet die Veränderung der Zellmembran, das sogenannte „Blebbling“. Es werden sogenannte „apoptotic bodies“ mit intakten Zellorganellen gebildet. Diese werden anschließend von angrenzenden Zellen oder Makrophagen phagozytiert. Der Grund hierfür ist es, eine Schädigung von Nachbarzellen zu vermeiden. Dieses kann mit Hilfe von FITC-Annexin V gebunden und sichtbar gemacht werden. Eine weitere Bindungmöglichkeit für FITC-Annexin V besteht bei destruierter Zellmembran, da dort eine Bindung an Phosphatidylserin intrazellulär stattfinden kann. Dies würde allerdings nicht in der frühen Apoptose auftreten, sondern nur in der späten, bei schon destruierter/fenestrierter Membran oder bei einer Zellnekrose. Zur Detektion von fenestrierten Membranen als Zeichen für eine Zellnekrose oder späte Apoptosephase wurden diese zusätlich mit Propidiumiodid (PI) angefärbt.

Es kann so eine Differenzierung in 3 Stadien erfolgen:

- Stadium I: lebendig

- Stadium II: früh-apoptotisch

- Stadium III: spät-apoptotisch
FITC-Annexin $\mathrm{V}$ negativ, PI negativ FITC-Annexin $\mathrm{V}$ positiv, PI negativ FITC-Annexin V positiv, PI positiv

Verwendet wurde das FITC-Annexin V Apoptosis Detection Kit 1 der Firma BD (BD Pharmingen $^{\mathrm{TM}}$; Kat.-Nr.:556547) und die FACS-Analyse (FacsCalibur; Firma BD). Verwendet wurde FITC-Annexin V (0,5ml; Kat.-Nr.:51-65874X), FITC-Annexin V Puffer (50ml; Kat.-Nr.:51-66121E; 10-fach konzentriert) und Propidiumiodid-Lösung (2ml; Kat.-Nr.:51-66211E), sowie in-vitro gezüchtete murine EPCs der Firma CELPROGEN® (1.2×murine EPCs; Kat.-Nr.:66110-37). Inkubiert wurden die Zellen jeweils für eine Stunde mit 250ng Ang-1 und TGF- $\beta$ als Apoptoseinduktor in einer Konzentration von $5 \mathrm{ng} / \mathrm{ml}$. Anschließend wurden die Zellkulturen in den 6-well-Platten zweimal mit 
PBS der Firma GIBCO („PBS“; pH Bereich 7,4+/-0,05; Kat.-Nr.:10010-015) gewaschen und anschließend mit 5ml 0,05\%igen Trypsins (Trypsin-EDTA der Firma GIBCO; Kat.Nr.:136861-8) von der Platte abgelöst. Resuspendierung fand mit $1 \times 10^{6}$ Zellen $/ \mathrm{ml}$ in verdünnter Pufferlösung statt. Anschließend wurden $100 \mu \mathrm{l}$ der Suspension $\left(1 \times 10^{5}\right.$ Zellen) in ein 5ml FACS-Röhrchen (5ml tube; Firma SARSTEDT; 75x12mm; Kat.-

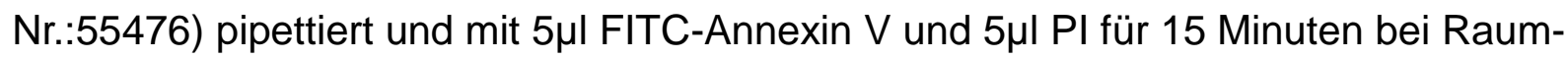
temperatur im Dunkeln inkubiert. Vor der FACS-Analyse wurden die FACS-Röhrchen mit $400 \mu$ verdünnter Pufferlösung aufgefüllt. Direkt erfolgte die Durchflusszytometrie. (FacsCalibur; Firma BD).

\subsection{Statistische Auswertung}

Die erhobenen Daten sind als Mittelwerte \pm standard error of the mean (SEM) angegeben. Der Beurteilung von statistisch signifikanten Unterschieden zwischen den Tieren der verschiedenen Gruppen diente der Mann-Whitney-Test. Ein signifikanter Unterschied wurde bei einem $p$-Wert von $<0,05$ postuliert. 


\section{Ergebnisse}

\subsection{Effekte von Angiopoetin-1-behandelten markierten EPCs auf die Nierenfunktion postischämischer C57/BI6N-Mäuse}

Wie bereits in der Einleitung ausgeführt, wurden erste Versuche über den Einsatz von Ang-1-behandelten EPCs im Rahmen des akuten ischämischen Nierenversagens der Maus bereits durch Herrn Dr. Jörg Rinneburger durchgeführt.

Seine Ergebnisse seien der Vollständigkeit halber sowie für ein besseres Verständnis der im Folgenden dargestellten Untersuchungen nochmals kurz zusammengefasst. Aus Experimenten aus dem Jahr 2007 war bekannt, dass sich ein ANV nicht mehr sicher verhindern lässt, wenn $0,5 \times 10^{6}$ unbehandelte Zellen nach einer bds. renalen Ischämie von 40 Minuten Dauer systemisch appliziert werden. Dies waren somit ideale Voraussetzungen, um mögliche agonistische Wirkungen verschiedener Substanzen zu testen. Um das homing der applizierten Zellen im postischämischen Verlauf besser beurteilen zu können, wurden die EPCs vor der Injektion mit einem speziellen Farbstoff markiert, dem so benannten Cell Trackerß. Nach Injektion von $0,5 \times 10^{6}$ Ang-1-behandelten Zellen verschlechterte sich die Nierenfunktion der behandelten Tiere signifikant (Abbildung 1).

Durch Koinkubation mit einem spezifischen Ang-1-blockierenden Peptid ließen sich diese Effekte (ebenfalls signifikant) abschwächen. Es wurde geschlussfolgert, dass Ang-1 den Zellen eine eher nephrodeletäre Potenz verleiht. 


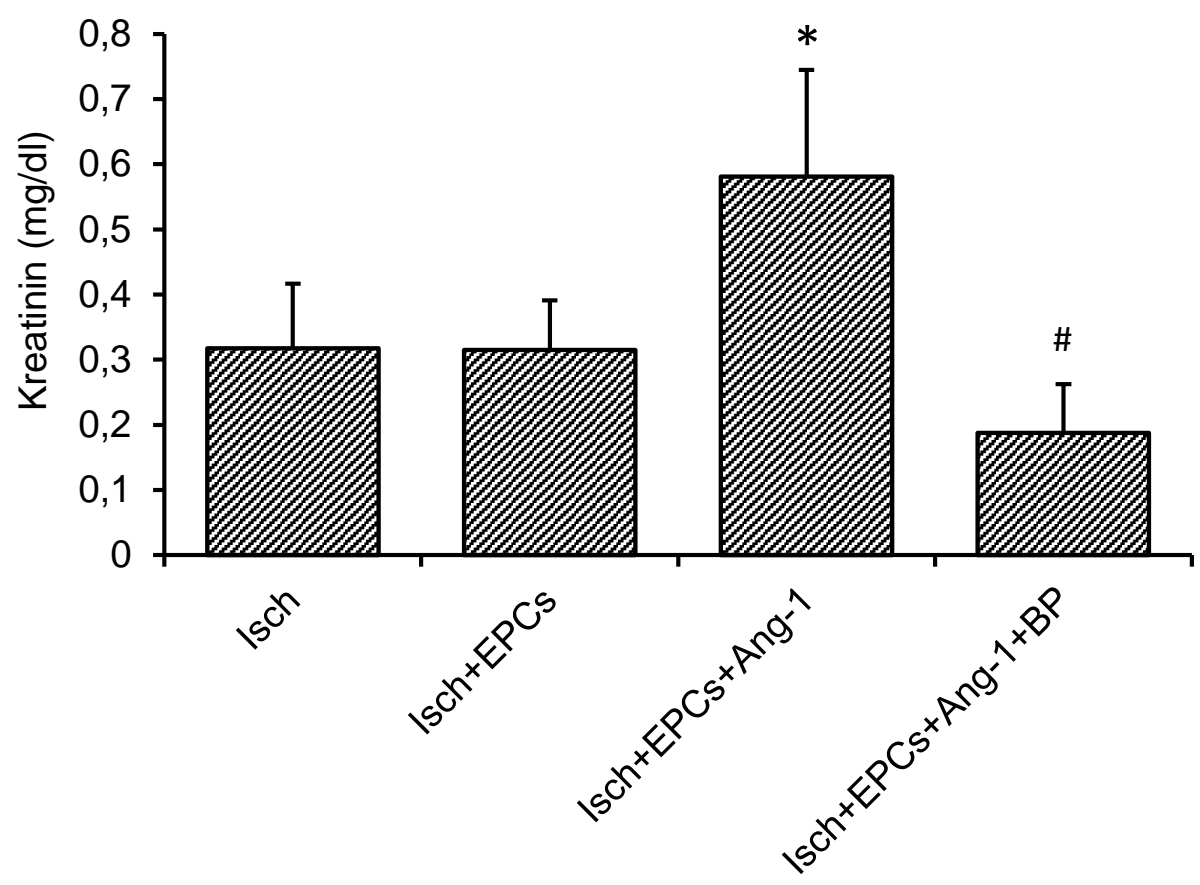

Abbildung 1: Resultate der Promotionsarbeit von Herrn Dr. J. Rinneburger. Effekte von Ang-1 auf EPCs beim murinen ischämischen ANV. Das Protein induzierte eine Verschlechterung der postischämischen Nierenfunktion zellbehandelter Tiere. Diese Wirkungen ließen sich mit Hilfe eines spezifischen Ang-1-blockierenden Peptids vollständig aufheben (Ergebnisse als MW \pm SEM, *: p-Wert im Vgl. zu „Isch+EPCs“<0,05; \#: p-Wert im Vgl. zu „Isch+EPCs+Ang-1“<0,05).

\subsection{Analyse des VE-Cadherinsystems}

In den ersten eigenen Versuchen wurde zunächst analysiert, ob die Verschlechterung der postischämischen Nierenfunktion von Mäusen nach Injektion Ang-1-behandelten EPCs eine Folge der Aktivierung des VE-Cadherinsystems sein kann. Ang-1 fungiert als Stimulator von VE-Cadherin, die Zelloberflächenexpression dieses Adhäsionsmoleküls der Cadherinfamilie nimmt unter dem Einfluss von Ang-1 zu (ZHAO et al. 2015). Im ersten Schritt wurde VE-Cadherin auf den Zellen selektiv antagonisiert. Diese mit 
Hilfe eines entsprechenden Antikörpers vermittelte Wirkung führte zu einer tendentiellen, jedoch nicht signifikanten weiteren Verschlechterung der Nierenfunktion postischämischer, zellinjizierter Mäuse. Es wurde geschlussfolgert, dass VE-Cadherin eher als endogener Agonist muriner EPCs beim ANV wirkt, hatte die Hemmung des Moleküls doch tendentiell eine weitere Intensivierung der renalen Dysfunktion zur Folge. Signifikante Unterschiede zwischen "Isch+EPCs+Ang-1" und "Isch+EPCs+Ang1+anti-VE-Cadherin“ ergaben sich keine. (Abbildung 2).

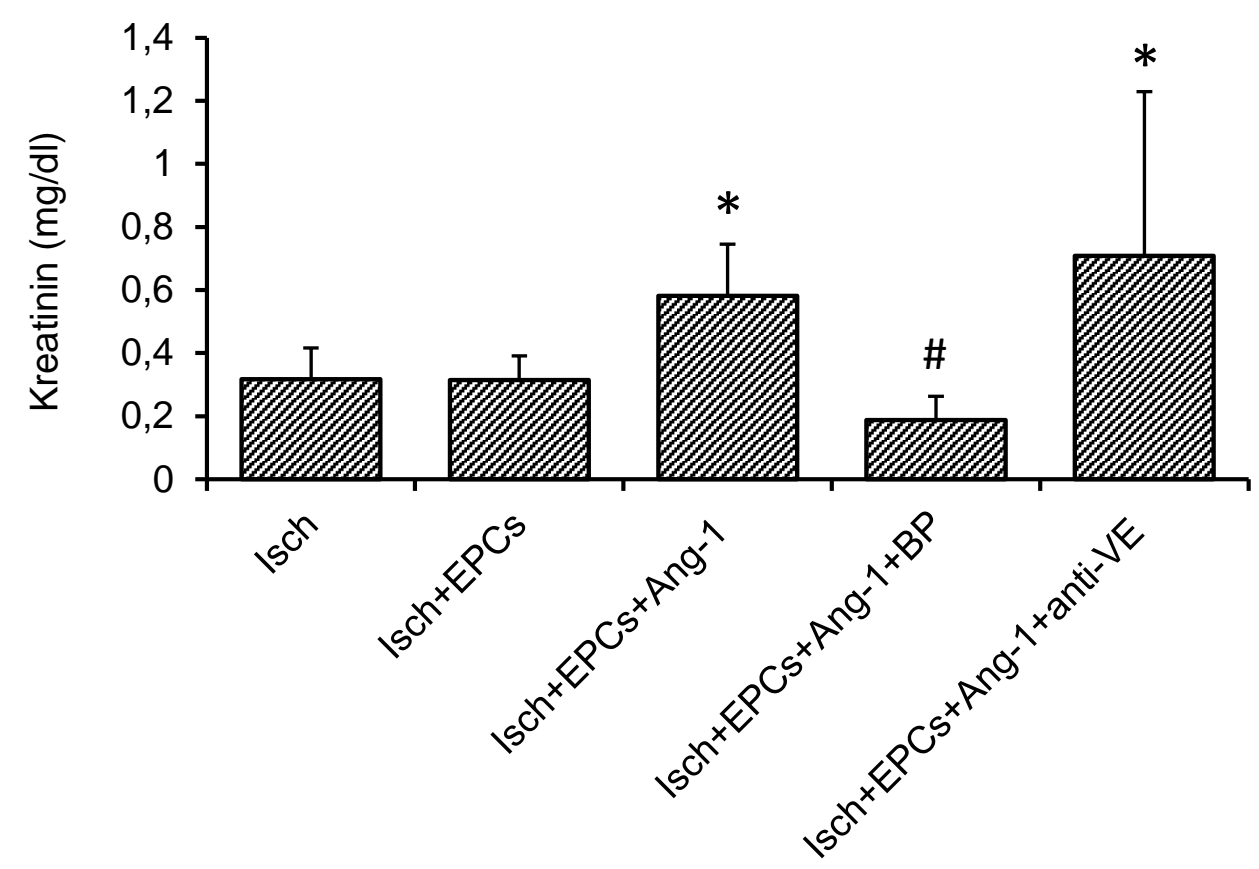

Abbildung 2: Effekte von Ang-1+anti-VE auf EPCs beim murinen ischämischen ANV. Das Protein induzierte in Kombination mit anti-VE eine weitere tendentielle, wenn auch nicht signifikante Verschlechterung der postischämischen Nierenfunktion zellbehandelter Tiere (Ergebnisse als MW \pm SEM, *: p-Wert im Vgl. zu „Isch-EPCs“<0,05; \#: pWert im Vgl. zu „Isch-EPCs+Ang-1“ <0,05; Gruppengrößen: Isch n=5; Isch+EPCs n=6; Isch+EPCs+Ang-1 n=6; Isch+EPCs+Ang-1+BP n=4; Isch+EPCs+Ang-1+anti-VE n=6) . 


\subsection{EPC-Produktion / Sekretion proangiogener Faktoren unter dem Einfluss von Angiopoetin-1}

Endothelial Progenitor Cells wirken insbesondere über indirekte Mechanismen vasoprotektiv. Dies bedeutet, die Zellen sezernieren im Gewebe verschiedene, potentiell proangiogene Mediatoren, welche vaskuläre Reparationsvorgänge stimulieren. Dementsprechend wurde nun die Freisetzung von vor allem VEGF unter dem Einfluss von Ang-1 untersucht. Es zeigten sich dabei keine Unterschiede zwischen unbehandelten und Ang-1-behandelten EPCs.

\subsection{EPC- / HUVEC-Migration unter dem Einfluss von Angiopoetin-1}

Vermehrte Migration von Zellen ist gemeinhin Ausdruck ihrer Aktivierung. Daher wurde einerseits das Migrationsverhalten von EPCs direkt sowie andererseits das Migrationsverhalten von kultivierten reifen Endothelzellen unter den Einfluss von Medium Ang-1-behandelter EPCs (indirekt) untersucht.

\subsubsection{Migration von EPCs (direkter Migrationsassay)}

In-vitro zeigte sich unter dem Einfluss von Ang-1 eine beschleunigte Wundokklusion durch migrierende EPCs Dieses Ergebnis stand in Kontrast zu den antagonistischen Effekten in-vivo (Abbildung 3). 


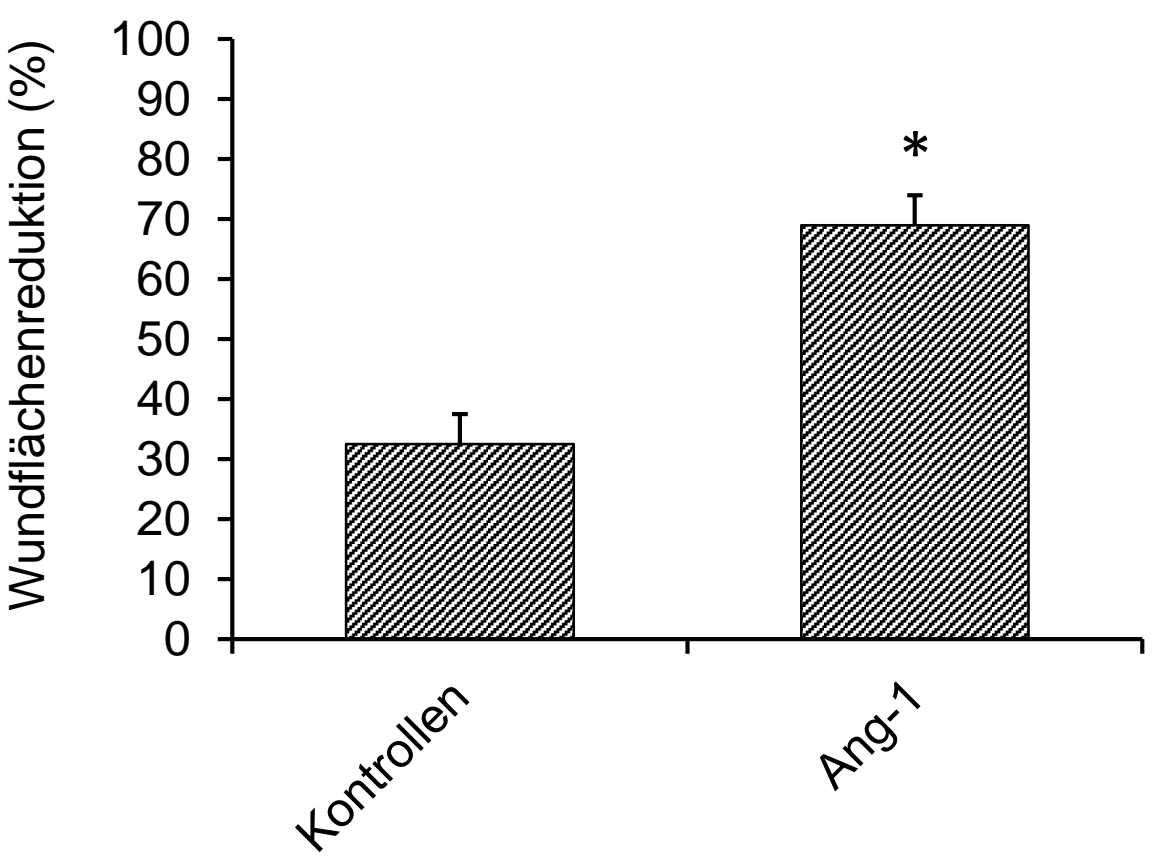

Abbildung 3: Effekte von Ang-1 auf die Migration kultivierter EPCs. Das Protein induzierte eine signifikant raschere in-vitro-Wundflächenokklusion (Ergebnisse als MW \pm SEM, $*: p<0,05 ; n=5)$.

\subsubsection{Migration von HUVECs}

Auch im indirekten Migrationsassay (Inkubation kultivierter HUVECs mit Überstand von Ang-1 behandelten EPCs) zeigte sich ein rascherer Wundflächenverschluss. Auch hier stand diese Beobachtung gleichfalls im Kontrast zu den vorbeschriebenen in-vivoDaten. 


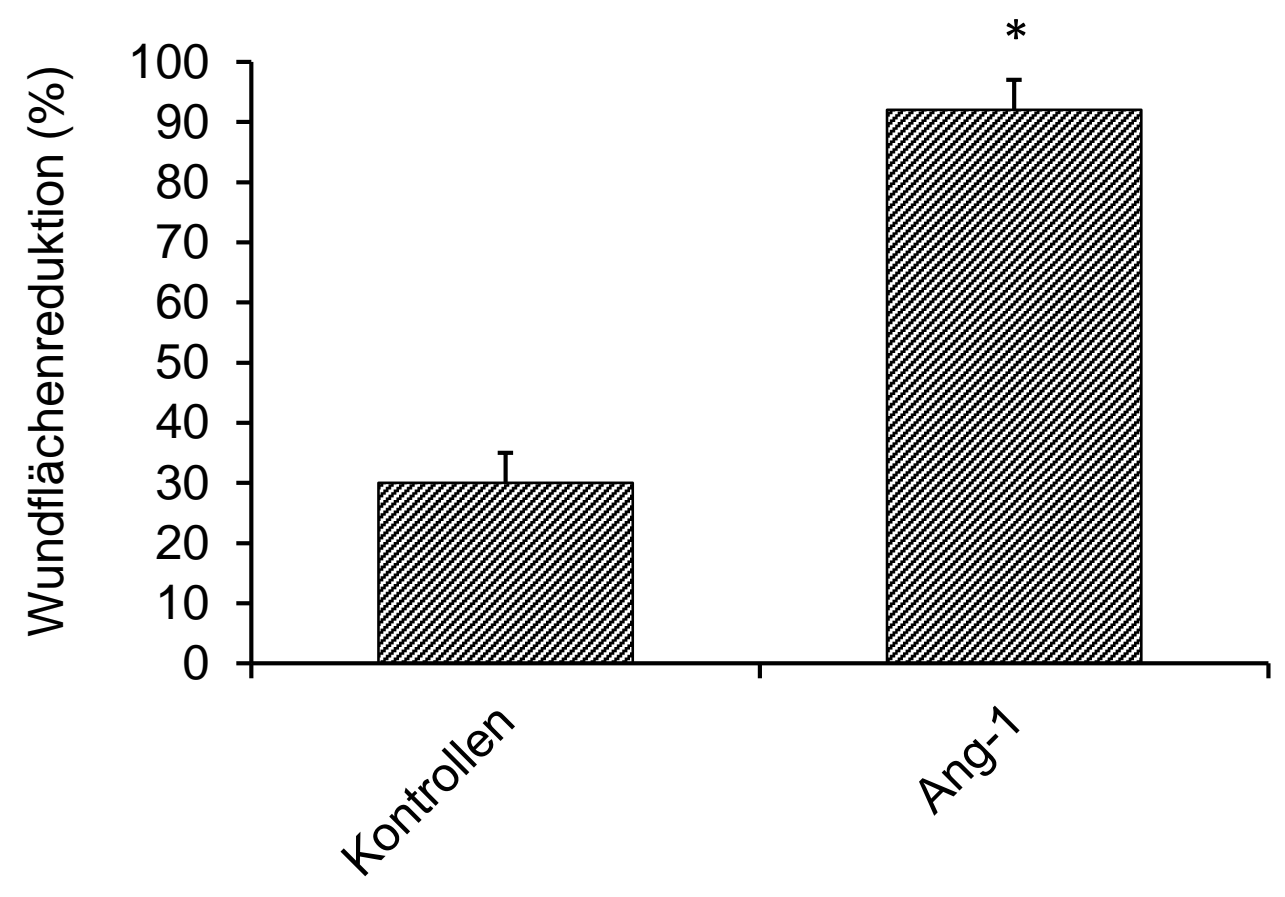

Abbildung 4: Effekte des Überstandes Ang-1 behandelten EPCs auf die Migration kultivierter HUVECs. Wie bereits im direkten Assay, wirken die Zellen (EPCs) indirekt proangiogen (Ergebnisse als MW $\pm S E M, *: p<0,05 ; n=5$ ).

\subsection{EPC-Überleben unter dem Einfluss von Angiopoetin-1}

Im nächsten Schritt wurde das „Überleben“ kultivierter, Transforming-Growth Factorbeta (TGF- $\beta$ ) behandelter EPCs unter dem Einfluss von Angiopoetin-1 untersucht. TGF- $\beta$ findet sich im postischämischen Nierengewebe in erhöhten Konzentrationen und kann als Induktor endothelialer Apoptose fungieren (GEWIN et al. 2012). Als Parameter des Zellüberlebends wurden AnnexinV+/ $\mathrm{Pl}^{+}$Zellen quantifiziert. Angiopoetin-1 reduzierte in mehreren Versuchen den Prozentsatz doppelt positiver Zellen Postischämie signifikant. Auch dieser Versuch zeigte für das Protein agonistische Wirkungen auf EPCs. 


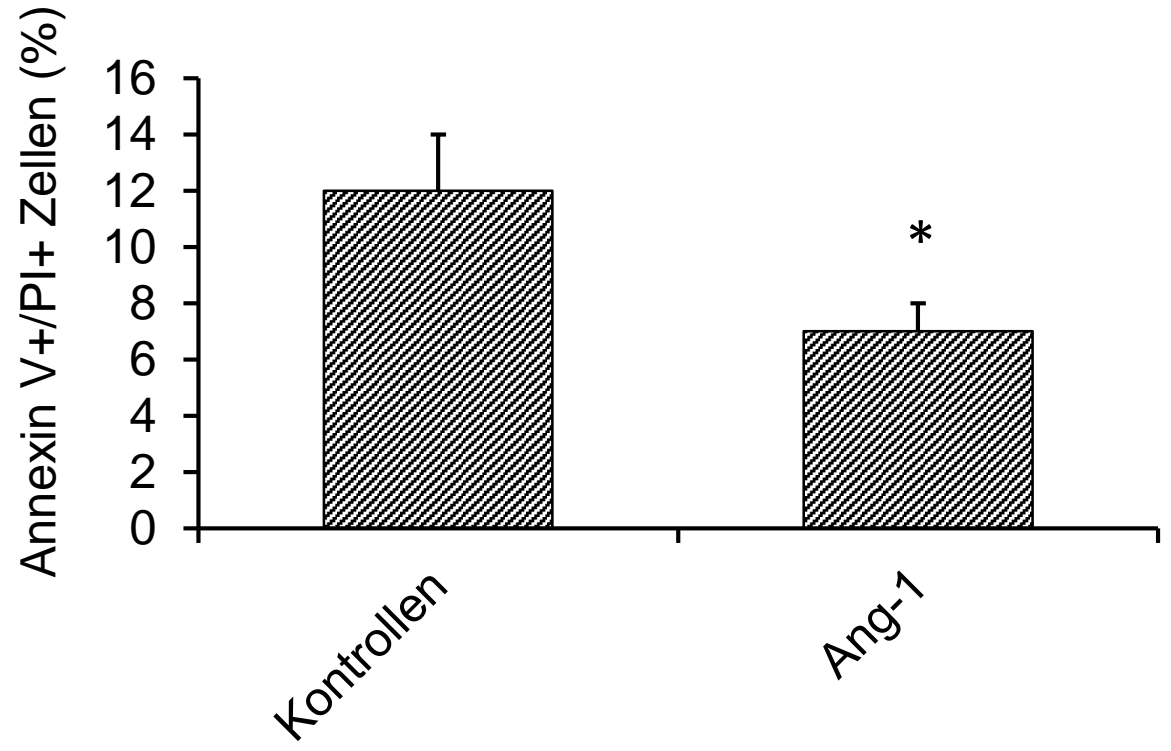

Abbildung 5: Modulation der TGF- $\beta$ reduziert EPC-Apoptose/Nekrose durch Angiopetin-1. Das Protein verlängerte das Zellüberleben signifikant. (Ergebnisse als MW $\pm S E M, *: p<0,05 ; n=5)$.

\subsection{Effekte von Angiopoetin-1-behandelten, nicht fluoreszenzmar- kierten EPCs auf die postischämischer Nierenfunktion}

In der letzten Versuchsreihe wurde analysiert, ob sich die von Herrn Dr. J. Rinneburger gesehene Effekte von EPCs auf die postischämische Nierenfunktion reproduzieren lassen, wenn die Zellen zuvor nicht mit einem Fluoreszenzfarbstoff markiert werden. Erstaunlicherweise zeigte sich beim Verzicht auf die Zellmarkierung eine signifikante Verbesserung der Nierenfunktion bei Injektion von $0,5 \times 10^{6}$ Ang-1 vorbehandelten EPCs (Abbildung 6). 


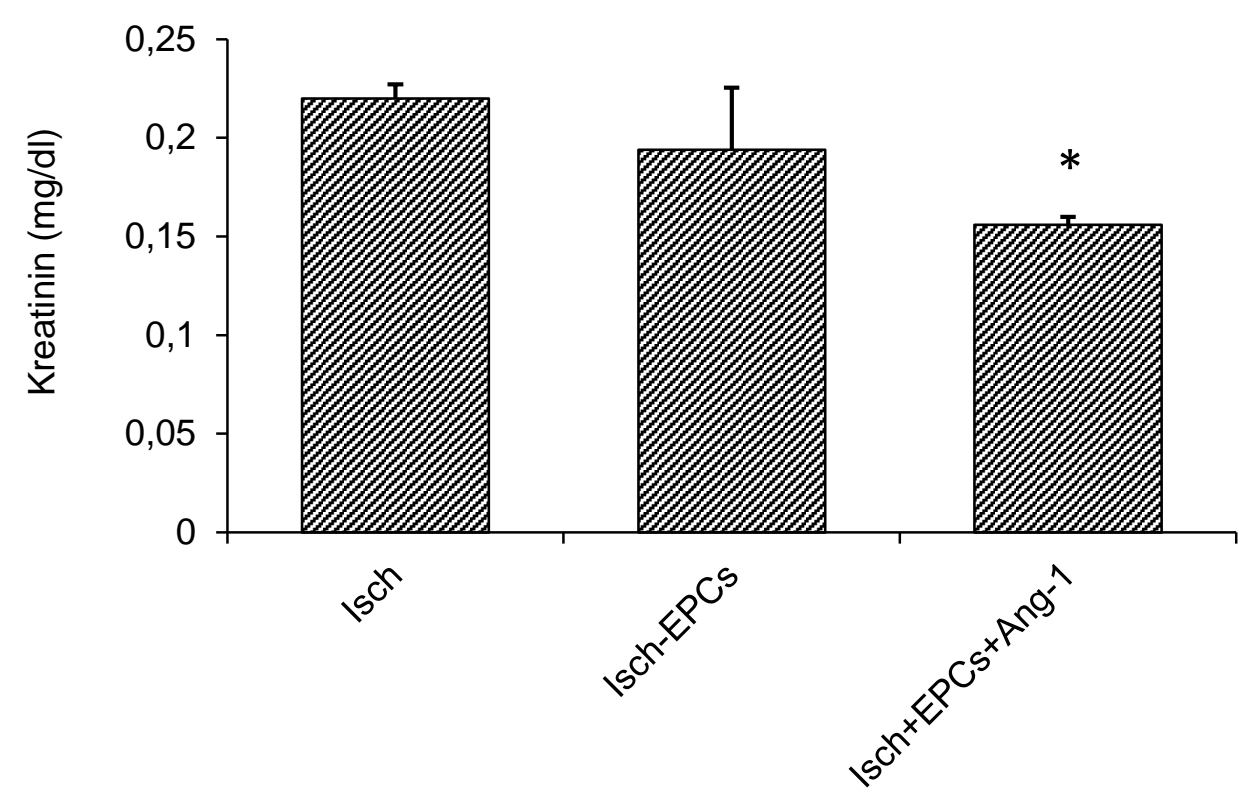

Abbildung 6: Effekte von Ang-1 auf unmarkierte EPCs beim murinen ischämischen ANV. Das Protein induzierte eine Verbesserung der postischämischen Nierenfunktion zellbehandelter Tiere. Durch den Verzicht auf Cell Tracker® kam es im Kontext mit Ang-1 zu einer signifikanten Verbesserung der Nierenfunktion (Ergebnisse als MW $\pm S E M, *: p<0,05$; Gruppengrößen: Isch n=6; Isch+EPCs n=5; Isch+EPCs+Ang-1 n=5). 


\section{Diskussion}

Im Rahmen der vorliegenden Arbeit wurde untersucht, ob die nephroprotektive Wirkung von Endothelvorläuferzellen auf das akute ischämische Nierenversagen durch Angiopoetin-1 verstärkt werden kann.

Die Ergebnisse der Experimente lassen sich wie folgt zusammenfassen:

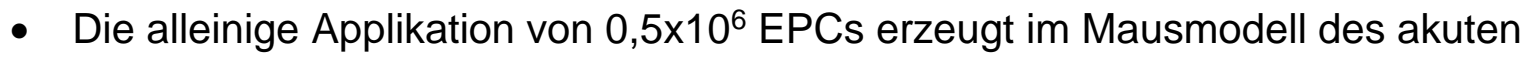
ischämischen Nierenversagens keinen signifikanten nephroprotektiven Effekt, sofern die Ischämiedauer bei 40 Minuten liegt.

- Die Applikation von $0,5 \times 10^{6}$ mit Angiopoetin-1 vorbehandelten EPCs verbessert die Nierenfunktion signifikant, sofern auf eine Zellmarkierung mittels Cell Tracker® verzichtet wird.

- In vitro zeigen sich unter dem Einfluss von Angiopoetin-1 folgende Effekte:

- eine beschleunigte Migration kultivierter EPCs,

- eine beschleunigte Migration kultivierter reifer Endothelzellen, wenn diese mit dem Überstand Ang-1-behandelten EPCs inkubiert werden sowie

- eine verminderte Apoptose/Nekrose von kultivierten EPCs.

- die zelluläre Sekretion des vasoprotektiven Faktors VEGF bleibt unter dem Einfluss des Proteins unverändert.

Ergänzend sei nochmals explizit erwähnt, dass eine Verschlechterung der postischämischen Nierenfunktion nach Gabe von Ang-1-behandelten EPCs nur dann bestand, wenn diese zuvor mit einem speziellen Farbstoff (Cell Tracker $\left.{ }^{\circledR}\right)$ inkubiert worden waren. Der Mechanismus dieser Effekte ist weiterhin unklar. Ein akutes ischämisches Nierenversagen ist auf morphologischer Ebene durch graduell unterschiedlich starke 
Alterationen der Tubulusepithelzellen gekennzeichnet. Die die Nierentubuli umgebenden Blutgefäße stehen in direktem Kontakt mit den Tubuluszellen und werden bei einem ANV gleichfalls merklich geschädigt. Die Schädigung kommt unter anderem in einem „Anschwellen“ der Endothelzellen zum Ausdruck. In der Konsequenz entsteht eine Einengung des Gefäßlumens mit anhaltender Minderperfusion des Organs. Sowohl die Tubuluszellen als auch die Endothelzellen zeichnen sich aber durch ein hohes Regenerationspotential aus.

Die Erholung der Endothelzellen kann mit Hilfe von EPCs signifikant verbessert werden, erste richtungsweisende Studien hierzu wurden vor ca. acht Jahren publiziert (PATSCHAN et al. 2006). Seinerzeit wurde belegt, dass EPCs bereits drei Stunden nach einer einseitigen Ischämie in den Milzen von Versuchsmäusen akkumulieren. Ischämische Präkonditionierungsbehandlung induzierte allerdings eine direkte Translokation mobilisierter Zellen ins postischämische Organ. Die aus den Nieren isolierten Zellen wurden in einem weiteren Schritt therapeutisch in Empfängertiere nach beidseits renaler Ischämie injiziert, dieser Schritt war mit deutlich nephroprotektiven Wirkungen verbunden (PATSCHAN et al. 2006).

Murine EPCs lassen sich mittlerweile mit großer Zuverlässigkeit isolieren und in Kultur vermehren. Eine Ende 2009 veröffentliche Studie belegte, dass syngene Zellen ein ischämisches ANV sicher verhindern können, wenn sie nach dem Ischämieende systemisch verabreicht werden. Allerdings nimmt die renoprotektive Wirkung einer definierten EPC-Population ab, wenn die Ischämiedauer ansteigt. (PATSCHAN et al. 2010). Basierend auf dieser Beobachtung wurde seither nach Strategien gesucht, welche die nephroprotektive Potenz von EPCs prinzipiell steigern könnten. Die diesbezüglich identifizierten pharmakologisch aktiven Wirkstoffe sollen an dieser Stelle nicht nochmals genauer diskutiert werden; es sei lediglich erwähnt, dass zum jetzigen Zeitpunkt 
bereits vier distinkte Mediatoren mit EPC-agonistischen Effekten identifiziert werden konnten. Da Angiopoetin-1 im Zusammenspiel mit VEGF stimulatorische Wirkungen auf reife Endothelzellen entfaltet (ABDEL-MALAK et al. 2009), galt dem Protein im Rahmen dieser Studie unser besonderes Augenmerk. Unsere Ergebnisse zeigten eine deutliche Verbesserung der Nierenfunktion von Mäusen, die Angiopoetin-1-behandelten EPCs erhalten hatten. Die Resultate der ergänzenden in-vitro-Versuche legen den verantwortlichen Mechanismus ansatzweise nahe. Zunächst steigert Ang-1 die Migration von EPCs sowie jene von reifen Endothelzellen, wenn diese mit dem Medium Angiopoetin-1-behandelter EPCs inkubiert werden. Des Weiteren reduziert Ang-1 die Apoptose/Nekrose kultivierter EPCs. Beide Beobachtungen deuten auf eine Stimulation der funktionellen Zellkompetenz.

Die Produktion/Sekretion des vasomodulierenden VEGF bleibt unter dem Einfluss von Angiopoetin-1 allerdings unbeeinflusst. Die Eigenschaft, das EPCs vorzugsweise über indirekte Mechanismen gefäßreparativ wirken, wurde in den letzten Jahren mehrfach bewiesen. Besonders in den Fokus gerückt sind diverse proangiogene Substanzen (VEGF, HGF, IGF-1), die von EPCs gebildet werden. Dadurch kommt es zu einer funktionellen „Rehabilitation“ ischämiegeschädigter Endothelzellen. Diese wird signifikant durch oben genannte Substanzen gefördert / beschleunigt (HUMPERT et al. 2008; IWABAYASHI et al. 2012; WAKUI et al. 2006). Unsere Daten zeigten, wie erwähnt, keine vermehrte Bildung des proangiogenen VEGF als repräsentativer Substanz. Dennoch ist es äußerst wahrscheinlich, dass Ang-1 die parakrine Aktivität der EPCs dahingehend moduliert, dass diese verstärkt endothelprotektiv im Organ wirken. Die hierfür verantwortlichen parakrinen Substanzen wurden aber offensichtlich in unserer Untersuchung nicht erfasst. Ein zweiter Mechanismus, der für die renale Funktionsverbes- 
serung nach Injektion Ang-1-behandelter EPCs verantwortlich sein könnte, ist die direkte Kontaktaufnahme zwischen EPCs und reifen Endothelien. Über diese können verschiedene zelluläre Komponenten von EPCs auf Endothelzellen übertragen werden. Tatsächlich ist dieser Prozess jedoch methodisch im lebenden Gewebe schwer zu erfassen und vermutlich findet eine direkte Kommunikation auch sehr früh nach Injektion von EPCs statt. In unseren Experimenten wurden die Tiere stets erst nach 48h analysiert. Im Übrigen fand sich in den Organen eine kaum relevante Anzahl von EPCs nach 48h. In jedem Fall bringen unsere Zellkulturversuche eine funktionelle Aktivierung von EPCs definitiv zum Ausdruck. Angiopoetin-1 führt zu einer deutlichen Verbesserung der protektiven Wirkung von EPCs, aber nur bei Verzicht Cell Tracker® . Dieser Zusammenhang und die negative Wirkung von Cell Tracker ${ }^{\circledR}$ ist so in der Literatur noch nicht beschrieben worden. Laut Herstellerhinweisen hat das Produkt keine Einwirkung auf die Zell-Vitalität und -Proliferation. Genauere Analysen der in vitro-Effekte des Substrates auf EPCs sind wohl erforderlich, um hier Klarheit zu schaffen.

EPCs könnten als Therapieoption des akuten ischämischen Nierenversagens zunehmend eine Alternative werden. Im Krankenhaus liegt die Inzidenz des ANV bei ca. 5\% und die intensivmedizinischen betreuten Patienten entwickeln in bis zu $30 \%$ der Fälle ein akutes Nierenversagen (KRIBBEN et al. 2003). Könnte der Verlauf eines ANV abgeschwächt werden, wäre für viele Patienten eine deutliche Verminderung des individuellen Leidens erreicht. Solche Therapiemaßnahmen wären auch unter finanziellen Gesichtspunkten sehr zu begrüßen.

Die bisherige Therapie umfasst einerseits kausale sowie konservativ symptomatische Maßnahmen, in schweren Fällen der Intoxikation ist eine Hämodialysetherapie unumgänglich. Zelltherapeutische Verfahren könnten jedoch zukünftig eine echte Alternative 
sein und in diesem Kontext eröffnen EPCs eine vielversprechende Perspektive. Auch in der kardiovaskulären Medizin sind die in der Geweberegeneration äußerst potent wirksam: adultes Knochenmark ist in der Lage, EPCs freizusetzen und z.B. nach einer Ischämie eine Neovaskularisation an den Myokardgefäßen zu veranlassen (TSE et al. 2007). Darüber hinaus wurde festgestellt, dass eine Korrelation zwischen der Anzahl an zirkulierenden EPCs und dem Auftreten von kardiovaskulären Ereignissen bei Patienten mit einer KHK gibt. Patienten mit einer KHK und einer niedrigen Anzahl an zirkulierenden EPCs wiesen eine höhere Inzidenz für kardiovaskuläre Ereignisse auf. (WERNER et al. 2007). Probleme für die klinische Anwendung am Menschen finden sich jedoch noch einige. Das ANV ist besonders bei intensivmedizinisch betreuten Patienten eine häufige Diagnose. Der genaue Zeitpunkt einer manifesten ischämischen Schädigung der Niere ist häufig nicht zu bestimmen. Sie kann sich binnen Stunden entwickeln und bedarf daher auch einer sehr zeitnahen Therapie. Für die Entwicklung eines ischämischen ANV weisen viele Patienten ein deutliches erhöhtes Risikoprofil (z.B. kardiale Insuffizienz, multiples Myelom mit Nierenbeteiligung und Diabetes mellitus) auf. Die langfristigen Auswirkungen einer diabetischen Stoffwechsellage auf die Struktur und Funktion der arteriellen Blutgefäße sind von großer Bedeutung. Es ist durchaus denkbar, dass die exogene Applikation/endogene Mobilisierung von EPCs in diesen Fällen über eine Verbesserung der Gefäßfunktion das Risiko einer renalen Organverschlechterung reduziert. An dieser Stelle ergibt sich ein weiteres Problem in der Anwendung von EPCs. Diese müssten in der Praxis rasch in größeren Mengen verfügbar sein. Weitere Probleme ergeben sich möglicherweise aus immunologischen Inkompatibilitäten, sofern Zellen aus anderen Spender-Organismen isoliert werden. Im 
Mausmodell wird diese Problematik durch die Verwendung syngener Zellen ausgeblendet. Daher ist eine Suche nach Stoffen, die das nephroprotektive Potential von EPCs merklich stimulieren, auch weiterhin in den Fokus der Forschung zu setzen. 


\section{Zusammenfassung}

In der vorliegenden Arbeit wurde untersucht, ob der nephroprotektive Effekt von EPCs durch eine Vorbehandlung mit Angiopoetin-1 verstärkt werden kann. Im Mausmodell wurde die linke Niere 40 Minuten abgeklemmt. Nach der Ischämiezeit wurde die entsprechende Suspension in das Gefäß der kontralateralen Niere injiziert und diese danach resiziert, so dass die komplette Nierenfunktion von der ischämisch vorgeschädigten Niere Übernommen wurde.

Nach Injektion von $0,5 \times 10^{6}$ nicht vorbehandelten EPCs kam es nicht zu einer signifikanten Nephroprotektion. Eine alleinige Vorbehandlung mit Angipoetin-1 führte hingegen zu einer deutlichen Verbesserung der Serumkreatininwerte.

Es wurde geschlussfolgert, dass Angiopoetin-1 den Zellen eine nephroprotektive Potenz verleiht. Des Weiteren wurde die Sekretion proangiogener Faktoren unter dem Einfluss von Angiopetin-1 untersucht. Die EPCs (Endothelial Progenitor Cells) wirken über indirekten Mechanismen vasoprotektiv, d.h. die Zellen sezernieren potentiell proangiogene Mediatoren, welche vaskuläre Reparationsvorgänge stimulieren. Es zeigten sich dabei keine Unterschiede in der Sekretion von VEGF zwischen unbehandelten und Ang-1-behandelten EPCs. In-vitro zeigte sich unter dem Einfluss von Angiopoetin1 eine signifikante Verbesserung der Wundflächenokklusion durch migrierende EPCs. Es wurde geschlussfolgert, dass Ang-1 EPC-agonstisch wirkt. Angiopoetin-1-behandelte EPCs stimulieren in-vitro die Migration von HUVECs (Human Umbilical Vein Endothelial Cells), d.h. Angiopoetin-1-behandelte EPCs wirken indirekt proangiogen. Es wurde geschlussfolgert, dass Angiopoetin-1-behandelte EPCs im Gegensatz zu der in-vivo-Untersuchung agonistisch wirken. Das in-vivo-Ergebnis wird mit einer bislang nicht beschriebenen negativen Wirkung des Cell Tracker ${ }^{\circledR}$ erklärt. Daraus lässt sich 
der klare Gegensatz zwischen in-vivo- und in-vitro-Ergebnissen begründen. Zusammenfassend wurde somit Ang-1 als neuer Agonist muriner EPCs beim ischämischen ANV identifiziert. 


\section{Anhang}

7.1 Tabellarische Zusammenfassung der verwendeten Chemikalien und Geräte

\begin{tabular}{|c|c|c|c|}
\hline Stoff & Herstellerfirma & Katalognummer & Verwendung \\
\hline Biocoll & BIOCHROM AG & L-6115 & $\begin{array}{l}\text { Dichtetrennung der } \\
\text { EPCs aus Vollblut } \\
\text { und Milz }\end{array}$ \\
\hline CCGM I Medium & CELPROGEN & M66110-37S & $\begin{array}{l}\text { Zellkulturen und } \\
\text { in vitro-Versuche }\end{array}$ \\
\hline CM Dil Zelltracker & INVITROGEN & C7000 & Markieren der Zellen \\
\hline Dil ac-LDL & INVITROGEN & L3484 & Markieren der Zellen \\
\hline Creatinin PAP & $\begin{array}{c}\text { TECHNIK EBERHARD } \\
\text { LEHMANN }\end{array}$ & LT-CR 0101 & $\begin{array}{c}\text { Kreatininbestimmung } \\
\text { im Serum }\end{array}$ \\
\hline EBM2 Medium & LONZA & CC-3156 & Verschiedenes \\
\hline Fibronectin & SIGMA - ALDRICH & F0895 - 1MG & Züchten der Zellen \\
\hline FITC & SIGMA-ALDRICH & L9006 & Züchtern der Zellen \\
\hline Formalin & MERCK & 1039992500 & Fixierung der Organe \\
\hline Glatine $2 \%$ & SIGMA & G1393 & $\begin{array}{l}\text { Beschichten der 24- } \\
\text { Well-Platten }\end{array}$ \\
\hline Heparin & RATIOPHARM & N21086.21-Z04 & $\begin{array}{l}\text { Hemmung der Blut- } \\
\text { gerinnung bei Zel- } \\
\text { lisolation }\end{array}$ \\
\hline Ketamine / Xylazine & SIGMA - ALDRICH & $\mathrm{K}-113$ & Anästhesie \\
\hline Angiopoetin-1 & Biocat & $4921-10$ & $\begin{array}{l}\text { Stimulieren der Zel- } \\
\text { len }\end{array}$ \\
\hline HUVEC & ATCC & PCS-100-013 & Zellen \\
\hline $\begin{array}{c}\text { Mouse Endothelial } \\
\text { Progenitor Cell Culture }\end{array}$ & CELPROGEN & $66110-37$ & $\begin{array}{c}\text { Zellen für die } \\
\text { in vitro-Versuche }\end{array}$ \\
\hline Phosphatpuffer & GIBCO & $10010-015$ & $\begin{array}{l}\text { Verdünnen von } \\
\text { Formalin, } \\
\text { Antikörpern und } \\
\text { DAPI }\end{array}$ \\
\hline Trypanblau & GIBCO & $15250-061$ & $\begin{array}{c}\text { Färben } \\
\text { abgestorbener Zellen }\end{array}$ \\
\hline VEGF ELISA Kit & RAYBIOTECH & ELM-VEGF-001 & $\begin{array}{c}\text { ELISA zur Bestimmung } \\
\text { der VEGF Freisetzung } \\
\text { aus EPCs }\end{array}$ \\
\hline Multikanalpipette & EPPENDORF & $4981000-019$ & Laborarbeiten \\
\hline Rotamax120 & HEIDOLPH & $54441200-00$ & Laborarbeiten \\
\hline FITC Annexin V & $\mathrm{BD}$ & 556547 & Laborarbeiten \\
\hline Trypsin-EDTA & GIBCO & $136861-8$ & Lösen der Zellen \\
\hline FACS-Röhrchen & SARSTEDT & 55476 & FACS-Analyse \\
\hline murinen EPCs & CELPROGEN & $66110-37$ & $\begin{array}{l}\text { Zellen für die in-vitro } \\
\text { Versuche }\end{array}$ \\
\hline
\end{tabular}




\begin{tabular}{|c|c|c|c|}
\hline HGF mouse ELISA & ABCAM & 100686 & $\begin{array}{c}\text { ELISA zur Bestim- } \\
\text { mung der HGF Frei- } \\
\text { setzung aus EPCs }\end{array}$ \\
\hline IGF-1 mouse ELISA & ABCAM & 100695 & $\begin{array}{c}\text { ELISA zur Bestim- } \\
\text { mung der IGF-1 Frei- } \\
\text { setzung aus EPCs }\end{array}$ \\
\hline
\end{tabular}

Tabelle 1: Liste der verwendeten Chemikalien mit Angabe von Firma und Katalognummer

\begin{tabular}{|c|c|c|}
\hline Gerät & Firma & Verwendung \\
\hline 75T Flasche (E66110-37-T75) & CELPROGEN & Zellkulturen \\
\hline $\begin{array}{c}\text { Ausgießstation (Tissue Block } \\
\text { Dispenser,) }\end{array}$ & MEDITE MEDIZINTECHNIK & $\begin{array}{l}\text { Herstellung der Paraffin- } \\
\text { schnitte }\end{array}$ \\
\hline $\begin{array}{l}\text { Chirurgische Pinzette } \\
\text { (Nr. 18057-14) }\end{array}$ & FINE SCIENCE TOOLS & $\begin{array}{c}\text { Operation (Applikation der } \\
\text { Klemme) }\end{array}$ \\
\hline Durchlichtmikroskop & ZEISS & Immunfluoreszenz-Histologie \\
\hline Faden (Nr. 100 6830) & HENRY SCHEIN & Operation (Nähen der Wunde) \\
\hline $\begin{array}{l}\text { Insulinspritze, Safety Glide } \\
\text { (Nr. 305930) }\end{array}$ & $\mathrm{BD}$ & $\begin{array}{c}\text { Operation (Injektion von Zellen } \\
\text { bzw. } \\
\text { Kochsalzlösung) }\end{array}$ \\
\hline Klemme (Nr. 18055-03) & FINE SCIENCE TOOLS & $\begin{array}{c}\text { Operation (Abklemmen der } \\
\text { Niere) }\end{array}$ \\
\hline Nadelhalter (Nr. 13004-14) & FINE SCIENCE TOOLS & Operation (Nähen der Wunde) \\
\hline Pinzette (Nr. 11608-15) & FINE SCIENCE TOOLS & Operation \\
\hline Pipette $(0,5-10 \mu \mathrm{l})$ & EPPENDORF & Laborarbeiten \\
\hline Pipette $(10-100 \mu l)$ & EPPENDORF & Laborarbeiten \\
\hline Pipette $(100-1000 \mu \mathrm{l})$ & EPPENDORF & Laborarbeiten \\
\hline $\begin{array}{l}\text { Pipettierspitzen für } 0,5-10 \mu \mathrm{l} \\
\text { Pipette }\end{array}$ & EPPENDORF & Laborarbeiten \\
\hline $\begin{array}{l}\text { Pipettierspitzen für } 10-100 \mu \mathrm{l} \\
\text { Pipette }\end{array}$ & EPPENDORF & Laborarbeiten \\
\hline $\begin{array}{c}\text { Pipettierspitzen für } 100-1000 \\
\mu \text { Pipette }\end{array}$ & EPPENDORF & Laborarbeiten \\
\hline Schere (Nr. 14058-11) & FINE SCIENCE TOOLS & Operation \\
\hline Spectrophotometer (UV-120-01) & SCHIMADZU & Kreatininbestimmung \\
\hline Zentrifuge (G5-6R) & BECKMANN & Zellisolation \\
\hline Zentrifuge (Rotixa/a) & HETTICH & In vitro-Versuche \\
\hline Photometerreader & TECA SPECTRA & ELISA Auswertung \\
\hline FacsCalibur & $\mathrm{BD}$ & Durchflusszytometrie \\
\hline
\end{tabular}

Tabelle 2: Liste der verwendeten Gerät 


\section{Literatur}

Abdel-Malak NA, Mofarrahi M, Mayaki D, Khachigian LM, Hussain SNA (2009): Early growth response-1 regulates angiopoietin-1-induced endothelial cell proliferation, migration, and differentiation. Arterioscler Thromb Vasc Biol 29, 209-216

Asahara T, Murohara T, Sullivan A, Silver M, van der Zee R, Li T, Witzenbichler B, Schatteman G, Isner JM (1997): Isolation of putative progenitor endothelial cells for angiogenesis. Science $\underline{275}, 964-967$

Asahara T, Masuda H, Takahashi T, Kalka C, Pastore C, Silver M (1999): Bone marrow origin of endothelial progenitor cells responsible for postnatal vasculogenesis in physiological and pathological neovascularization. Circ Res $\underline{85,221-8}$

Bailey AS, Jiang S, Afentoulis M, Baumann Cl, Schroeder DA, Olson SB, Wong MH, Fleming WH (2004): Transplanted adult hematopoietic stems cells differentiate into functional endothelial cells. Blood $\underline{103}, 13-19$

Baldwin H S, Shen H M, Yan H C, DeLisser H M, Chung A, Mickanin C, Trask T, Kirschbaum N E, Newman P J und Albelda S M (1994): Platelet endothelial cell adhesion molecule-1 (PECAM-1/CD31): alternatively spliced, functionally distinct isoforms expressed during mammalian cardio-vascular development. Development $\underline{120}, 2539-53$ Beltrami AP, Barlucchi L, Torella D, Baker M, Limana F, Chimenti S, Kasahara H, Rota M, Musso E, Urbanek K, Leri A, Kajstura J, Nadal-Ginard B, Anversa P (2003): Adult cardiac stem cells are multipotent and support myocardial regeneration. Cell $\underline{114}, 763-$ 776 
Blann, A. D., Woywodt, A., Bertolini, F., Bull, T. M., Buyon, J. P., Clancy, R. M., Haubitz, M., Hebbel, R. P., Lip, G. Y. H., Mancuso, P., Sampol, J., Solovey, A., Dignat-George, F. (2005): Circulating endothelial cells, Biomarker of vascular disease. Thromb Haemost $\underline{93}, 228-35$

Brindle NP, Saharinen P, Alitalo K (2006): Signaling and functions of angiopoietin-1 in vascular protection. Circ Res $\underline{98}, 1014-1023$

Brodsky S V, Yamamoto T, Tada T, Kim B, Chen J, Kajiya F und Goligorsky M S (2002):

Endothelial dysfunction in ischemic acute renal failure:rescue by transplanted endothelial cells. Am J Physiol 282, 1140-9

Burger D. (2015): Human Endothelial Colony-Forming Cells Protect against Acute Kidney Injury. The American Journal of Pathology $\underline{8}, 2309-2323$

Case J, Mead LE, Bessler WK, Prater D, White HA, Saadatzadeh MR, Bhavsar JR, Yoder MC, Haneline LS, Ingram DA (2007): Human CD34+AC133+VEGFR-2+ cells are not endothelial progenitor cells but distinct, primitive hematopoietic progenitors. Exp Hematol 35, $1109-1118$

Cantaluppi V, Gatti S, Medica D, Figliolini F, Bruno S, Deregibus MC, et al. (2012): Microvesicles derived from endothelial progenitor cells protect the kidney from ischemia-reperfusion injury by microRNA-dependent reprogramming of resident renal cells. Kidney Int $\underline{82}, 412-27$

Devanesan AJ, Laughlan KA, Girn HR, Homer-Vanniasinkam S. (2009): Endothelial progenitor cells as a therapeutic option in peripheral arterial disease. Eur J Vasc Endovasc Surg $\underline{38,475-81}$

Fadini GP, Losordo D, Dimmeler S. (2012): Critical reevaluation of endothelial progenitor cell phenotypes for therapeutic and diagnostic use. Circ Res $\underline{110,624-37}$ 
Gewin L1, Vadivelu S, Neelisetty S, Srichai MB, Paueksakon P, Pozzi A, Harris RC, Zent R. (2012): Deleting the TGF- $\beta$ receptor attenuates acute proximal tubule injury. J Am Soc Nephrol $\underline{23}$

Grant M B, May W S, Caballero S, Brown G A J, Guthrie S M, Mames R N, Byrne B J, Vaught T, Spoerri P E, Peck A B und Scott E W (2002): Adult hematopoietic stem cells provide functional hemangioblast activity during retinal neovascularization. Nat Med $\underline{8}$, $607-612$

Goligorsky M S (2005): Endothelial cell dysfunction: Am J Physiol 288, 871-80

Goligorsky MS, Yasuda K, Ratliff B. (2010): Dysfunctional endothelial progenitor cells in chronic kidney disease. J Am Soc Nephrol 21, 911-9

Humpert PM, Djuric Z, Zeuge U, Oikonomou D, Seregin Y, Laine K, Eckstein V, Nawroth PP, Bierhaus A (2008): Insulin Stimulates the Clonogenic Potential of Angiogenic Endothelial Progenitor Cells by IGF-1 Receptor-Dependent Signaling. Mol Med $\underline{14}$, 301-308

Iwabayashi M, Taniyama Y, Sanada F, Azuma J, lekushi K, Okayama K, Chatterjee A, Rakugi H, Morishita R (2012): Inhibition of Lp(a)-induced Functional Impairment of Endothelial Cells and Endothelial Progenitor Cells by Hepatocyte Growth Factor. Biochem Biophys Res Commun $\underline{423}$, 79-84

Kawamoto A, Asahara T, Losordo DW. (2002): Transplantation of endothelial progenitor cells for therapeutic neovascularization. Cardiovasc Radiat Med $\underline{3}, 221-5$

Khakoo Finkel T (2005): Endothelial progenitor cells. Annu Rev Med $\underline{56}, 79-101$ 
Kim I, Kim HG, Moon SO, Chae SW, So JN, Koh KN, Ahn BC, Koh GY (2000): Angiopoietin-1 induces endothelial cell sprouting through the activation of focal adhesion kinase and plasmin secretion. Circ Res $\underline{86}, 952-959$

Koblizek TI, Weiss C, Yancopoulos GD, Deutsch U, Risau W (1998): Angiopoietin-1 induces sprouting angiogenesis in vitro. Curr Biol $\underline{8}, 529-532$

Kribben A, Herget-Rosenthal S, Pietruck P, Philipp T (2003): Acute renal failure-an review. Dtsch med Wochenschr $\underline{128}, 1231-1236$

Leaf A (1973): Cell swelling. A factor in ischemic tissue injury. Circulation $\underline{48}$, $455-458$

Lin Y, Weisdorf DJ, Solovey A, Hebbel RP. (2000): Origins of circulating endothelial cells and endothelial outgrowth from blood. J Clin Invest $\underline{105,71-7}$

Linares PM, Chaparro M, Gisbert JP. (2014): Angiopoietins in inflammation and their implication in the development of inflammatory bowel disease. A review. J Crohns Colitis $\underline{8}, 183-90$

Maisonpierre PC, Suri C, Jones PF, Bartunkova S, Wiegand SJ, Radziejewski C, Compton D, McClain J, Aldrich TH, Papadopoulos N, Daly TJ, Davis S, Sato TN, Yancopoulos GD (1997): Angiopoietin-2, a natural antagonist for Tie2 that disrupts in vivo angiogenesis. Science $\underline{277}, 55-60$

Moubarik C, Guillet B, Youssef B, Codaccioni J-L, Piercecchi M-D, Sabatier F. (2011): Transplanted late outgrowth endothelial progenitor cells as cell therapy product for stroke. Stem Cell Rev 7, 208-20 
Patschan D, Krupincza K, Patschan S, Zhang Z, Hamby C, Goligorsky MS (2006): Dynamics of mobilization and homing of endothelial progenitor cells after acute renal ischemia: modulation by ischemic preconditioning. Am J Physiol 291, 176-185

Patschan D, Plotkin M, Goligorsky M S (2006a): Therapeutic use of stem and endothelial progenitor cells in acute renal injury. Curr Opin Pharmacol $\underline{6}, 176-83$

Patschan D, Hildebrandt A, Rinneburger J, Wessels JT, Patschan SA, Becker JU, Henze E, Kruger A, Muller GA (2012): The hormone Melatonin stimulates renoprotective effects of early outgrowth endothelial progenitor cells in acute ischemic kidney injury. Am J Physiol 302,1305-12

Patschan D, Patschan S, Wessels JT, Becker JU, David S, Henze E, Goligorsky MS, Müller GA (2010). Epac-1 activator 8-O-cAMP augments renoprotective effects of syngeneic [corrected] murine EPCs in acute ischemic kidney injury. Am J Physiol $\underline{298}$, $78-85$

Patschan D, Rinneburger J, Backhaus R, Schwarze K, Henze E, Patschan S, Müller G (2013): Angiopoietin-1 treated early endothelial outgrowth cells (eEOCs) are activated in vitro and reduce renal damage in murine acute ischemic kidney injury (iAKI). BMC Nephrology 14, 227

Patschan D, Backhaus R, Elle HJ, Schwarze K, Henze E, Becker JU, Patschan S, Müller GA (2013): Angiopoietin-2 modulates eEOC-mediated renoprotection in AKI in a dose-dependent manner. J Nephrol $\underline{26}, 667-74$

Patschan D, Schwarze K, Lange A, Meise N, Henze E, Becker JU, Patschan S, Müller GA (2013): Bone morphogenetic protein-5 and early endothelial outgrowth cells (eEOCs) in acute ischemic kidney injury (AKI) and 5/6-chronic kidney disease. Am J Physiol $\underline{305}, 314-22$ 
Patschan D, Schwarze K, Henze E, Patschan S, Müller GA. (2015): Endothelial autophagy and Endothelial-to-Mesenchymal Transition (EndoMT) in eEPC treatment of ischemic AKI. J Nephrol $\underline{29}, 637-44$

Pfaff, D., Fiedler, U. \& Augustin, H.G. (2006): Emerging roles of the Angiopoietin-Tie and the ephrin-Ephsystems as regulators of cell trafficking. Journal of leukocyte biology $\underline{80}, 719-726$

Planat-Benard V, Silvestre S J, Cousin B, Andr M, Nibbelink M, Tamarat R, Clergue M, Manneville C, Saillan-Barreau C, Duriez M, Tedgui A, Levy B, Pnicaud L und Casteilla L (2004): Plasticity of human adipose lineage cells toward endothelial cells: physiological and therapeutic perspectives. Circulation $\underline{109}, 656-663$

Rafii Lyden D (2003): Therapeutic stem and progenitor cell transplanta-tion for organ vascularization and regeneration. Nat Med $\underline{9} 702-12$

Rehman J, Li J, Orschell C M und March K L (2003): Peripheral blood "endothelial progenitor cells" are derived from monocyte/macrophages and secrete angiogenic growth factors. Circulation $\underline{107}, 1164-1169$

Reyes M, Dudek A,Jahagirdar B, Koodie L, Marker P H und Verfaillie C M (2002): Origin of endothelial progenitors in human postnatal bone mar-row. J Clin Invest $\underline{109}$ $337-46$

Richardson MR, Yoder MC. (2011): Endothelial progenitor cells: quo vadis. J Mol Cell Cardiol $\underline{50}, 266-72$

Romagnani P, Annunziato F, Liotta F, Lazzeri E, Mazzinghi B, Frosali F, Cosmi L, Maggi L, Lasagni L, Scheffold A, Kruger M, Dimmeler S, Marra F, Gensini G, Maggi E, Romagnani S (2005): CD14+CD34low cells with stem cell phenotypic and functional features are the major source of circulating endothelial progenitors. Circ Res $\underline{97}, 314-322$ 
Santulli G. (2014): Angiopoietin-like proteins: a comprehensive look. Front Endocrinol. $\underline{5,} 4$

Schon, M., Kahne, T., Gollnick, H., et al. (2005): Expression of gp 130 in tumors and inflammatory disorders of the skin: Formal proof of its identity as CD146 (MUC18, MelCAM). J Invest Dermatol $\underline{125}, 353-363$

Schuster MD, Kocher AA, Seki T, Martens TP, Xiang G, Homma S. (2004): Myocardial neovascularization by bone marrow angioblasts results in cardiomyocyte regeneration. Am J Physiol Heart Circ Physiol 287, 525-32

Shaffer RG, Greene S, Arshi A, Supple G, Bantly A, Moore JS. (2006): Effect of acute exercise on endothelial progenitor cells in patients with peripheral arterial disease. Vasc Med Lond Engl 11, 219-26

Tse HF, Yiu KH,Lau CP (2007): Bone Marrow Stem Cell Therapy for Myocardial Angiogenesis. Curr Vasc Pharmacol $\underline{5}, 103-112$

Urbich C Dimmeler S (2004a): Endothelial progenitor cells functional characterization. Trends Cardiovasc Med 14, 318-322

Urbich C Dimmeler S (2004b): Endothelial progenitor cell: characterization and role in vascular biology. Circ Res $\underline{95}, 343-353$

Wakui S, Yokoo K, Muto T, Suzuki Y, Takahashi H, Furusato M, Hano H, Endou H und Kanai Y (2006): Localization of Ang-1, -2, Tie-2, and VEGF expression at endothelialpericyte interdigitation in rat angiogenesis. Lab Invest $\underline{\text { 86, }}$ 1172-1184

Werner N, Wassmann S, Ahlers P, Schiegl T, Kosiol S, Link A, Walenta K, Nickenig G (2007): Endothelial progenitor cells correlate with endothelial function in patients with coronary artery disease. Basic Res Cardiol 102, 565-571 
Yamamoto T, Tada T, Brodsky SV, Tanaka H, Noiri E, Kajiya F, Goligorsky MS (2002): Intravital videomicroscopy of peritubular capillaries in renal ischemia. Am J Physiol 282, $1150-1155$

Yoder M C, Mead L E, Prater D, Krier T R, Mroueh K N, Li F, Krasich R, Temm C J, Prchal J T und Ingram D A (2007): Redefining endothelial cells via clonal analysis and hematopoietic stem/progenitor cell principals. Blood $\underline{109}, 1801-9$

Zhao YH, Yuan B, Chen J, Feng DH, Zhao B, Qin C. (2013): Endothelial progenitor cells: therapeutic perspective for ischemic stroke. CNS Neurosci Ther $\underline{19}, 67-75$

Zhao J, Chen L, Shu B, Tang J, Zhang L, Xie J, Liu X, Xu Y, Qi S, (2015): Angiopoietin1 protects the endothelial cells against advanced glycation end product injury by strengthening cell junctions and inhibiting cell apoptosis. Am J Physiol 230, 1895-905 


\section{Danksagung}

Zuerst möchte ich Herrn Prof. Dr. med. G.A. Müller für die Möglichkeit danken, in seiner Abteilung promovieren zu dürfen. Mein größter Dank gilt meinem sehr geschätzten Doktorvater Prof. Dr. med. Daniel Patschan, Oberarzt in der Klinik für Nephrologie und Rheumatologie des Universitätsklinikums Göttingen. Weit wichtiger noch war aber das freundschaftliche Vertrauen, das er stets in mich und meine Arbeit gesetzt hat und das mir immer der größte Ansporn für meine Arbeit war und ist. Ohne diese Art der Unterstützung wäre die vorliegende Arbeit nicht zustande gekommen. Des Weiteren danke ich Dipl. Biologin Frau Elvira Henze und Katrin Schwarze für ihre großzügige Unterstützung im Labor. Den Mitarbeitern des Tierstalles danke ich für die Bereitstellung und Pflege der Mäuse. Meinen Kollegen Dr. J. Rinneburger danke ich für die sehr gute und konstruktive Zusammenarbeit. 